\title{
Impairment of Intestinal Monocarboxylate Transporter 6 Function and Expression in Diabetic Rats Induced by Combination of High-Fat Diet and Low Dose of Streptozocin: Involvement of Butyrate- Peroxisome Proliferator-Activated Receptor- $\gamma$ Activation $^{\text {[ }}$
}

\author{
Feng Xu, Liang Zhu, Chaoqun Qian, Junjie Zhou, Donghao Geng, Ping Li, Wenjing Xuan, \\ Fangge Wu, Kaijing Zhao, Weimin Kong, Yuanyuan Qin, Limin Liang, Li Liu, ${ }^{1}$ and Xiaodong Liu ${ }^{1}$ \\ Center of Drug Metabolism and Pharmacokinetics, College of Pharmacy, China Pharmaceutical University, Nanjing, People's \\ Republic of China
}

Received December 12, 2018; accepted March 26, 2019

\begin{abstract}
Generally, diabetes remarkably alters the expression and function of intestinal drug transporters. Nateglinide and bumetanide are substrates of monocarboxylate transporter 6 (MCT6). We investigated whether diabetes down-regulated the function and expression of intestinal MCT6 and the possible mechanism in diabetic rats induced by a combination of high-fat diet and low-dose streptozocin. Our results indicated that diabetes significantly decreased the oral plasma exposure of nateglinide. The plasma peak concentration and area under curve in diabetic rats were $16.9 \%$ and $\mathbf{2 8 . 2 \%}$ of control rats, respectively. Diabetes significantly decreased the protein and mRNA expressions of intestinal MCT6 and oligopeptide transporter 1 (PEPT1) but up-regulated peroxisome proliferator-activated receptor $\gamma$ (PPAR $\gamma$ ) protein level. Single-pass intestinal perfusion demonstrated that diabetes prominently decreased the absorption of nateglinide and bumetanide. The МСТ6 inhibitor bumetanide, but not PEPT1 inhibitor glycylsarcosine, significantly inhibited intestinal absorption of
\end{abstract}

nateglinide in rats. Coadministration with bumetanide remarkably decreased the oral plasma exposure of nateglinide in rats. High concentrations of butyrate were detected in the intestine of diabetic rats. In Caco-2 cells (a human colorectal adenocarcinoma cell line), bumetanide and MCT6 knockdown remarkably inhibited the uptake of nateglinide. Butyrate down-regulated the function and expression of MCT6 in a concentration-dependent manner but increased PPAR $\gamma$ expression. The decreased expressions of MCT6 by PPAR $\gamma$ agonist troglitazone or butyrate were reversed by both PPAR $\gamma$ knockdown and PPAR $\gamma$ antagonist 2-chloro-5-nitro- $N$-phenylbenzamide (GW9662). Four weeks of butyrate treatment significantly decreased the oral plasma concentrations of nateglinide in rats, accompanied by significantly higher intestinal PPAR $\gamma$ and lower MCT6 protein levels. In conclusion, diabetes impaired the expression and function of intestinal MCT6 partly via butyrate-mediated PPAR $\gamma$ activation, decreasing the oral plasma exposure of nateglinide.
This work was supported by the National Science Foundation of China (No. 81573490, 81872930, 81373273 and81673505); National Science Foundation of Jiangsu Province (BK20161457); "Cyan Blue," "Six Talent Peaks" and "333" Project of Jiangsu Province and "Double First-Class" university project (No. CPU2018GY22).

${ }^{1} \mathrm{~L}$. Liu and X. Liu are co-corresponding authors.

https://doi.org/10.1124/dmd.118.085803.

S This article has supplemental material available at dmd.aspetjournals.org.

\section{Introduction}

Nateglinide, a substrate of monocarboxylate transporter 6 (MCT6) (Kohyama et al., 2013), is used widely for treatment of type II diabetes via stimulating transient secretion of insulin in pancreatic $\beta$-cells (Halas, 2001). Pharmacokinetic data show that the compound possesses rapid absorption, high bioavailability ( $\sim 72 \%-90 \%)$, and minimal first-pass effect (Karara et al., 1999). In humans, nateglinide is predominantly metabolized by hepatic cytochrome P450 enzyme 2C9 (CYP2C9) $(\sim 96 \%)$ and partly by CYP3A4 $(\sim 4 \%)$. Its main metabolite is $N$ [trans-4-(1-hydroxy-1-methylethyl)-cyclohexanecarbonyl]-D-phenylalanine

ABBREVIATIONS: AUC, area under the curve; BCRP, breast cancer resistance protein; Caco-2, human colorectal adenocarcinoma cell line; $\mathrm{CL}_{\text {int }}$, intrinsic clearance; CON, control; CYP, cytochrome P450 enzyme; DM, diabetes mellitus; FBG, fasting glucose in blood; FINS, fasting insulin; G-6PDH, glucose-6-phosphate dehydrogenase; G-6-P, D-glucose-6-phosphate; Gly-Sar, glycylsarcosine; GW9662, 2-chloro-5-nitro-Nphenylbenzamide; HBSS, Hanks' balanced salt solution; HFD, high-fat diet; HOMA-IR, homeostasis model assessment - insulin resistance; Ko143 (tert-butyl 3-[(2S, 5S,8S)-14-methoxy-2-(2-methylpropyl)-4,7-dioxo-3,6,17-triazatetracyclo[8.7.0.0 $\left.0^{3,8} .0^{11,16}\right]$ heptadeca-1(10),11,13,15tetraen-5-yl]propanoate); LC-MS, liquid chromatography with mass spectrometry; MCT6, monocarboxylate transporter 6; M1, $N$-[trans-4-(1hydroxy-1-methylethyl)-cyclohexanecarbonyl]-D-phenylalanine; MRP4, multidrug resistance protein 4; NKCC, sodium-potassium-2chloride cotransporter; OAT2, organic anion transporter 2; OATPs, organic anion-transporting polypeptides; OCTs, organic cation transporters; $\mathrm{P}_{\text {eff }}$, apparent effective permeability; PEPT, oligopeptide transporter; P-GP, P-glycoprotein; PPAR $\gamma$, peroxisome proliferator-activated receptor $\gamma$; qRT-PCR, quantitative real-time polymerase chain reaction; RIPA, radioimmunoprecipitation assay; SCFA, short-chain fatty acids; siRNA, small interfering RNA; SPIP, single-pass intestinal perfusion; STZ, streptozocin; TC, total cholesterol; TG, triglyceride. 
(termed as M1), accounting for about $62 \%$ to $66 \%$ of the nateglinide dose (Takanohashi et al., 2007). It was found that diabetes did not alter the pharmacokinetics of nateglinide after its intravenous administration to Goto-Kakizaki rats (Tamura et al., 2010), although some studies reported that diabetic rats induced by streptozocin (STZ) showed significantly lower expressions of hepatic CYP2C11 (Liu et al., 2012) and intestinal CYP3A1/2 but higher expression of hepatic CYP3A1/2 (Hu et al., 2011). CYP2C11 and CYP3A1/2 in rats correspond to the human orthologs CYP2C9 and CYP3A4 (Martignoni et al., 2006), respectively. Our preliminary experiments found that the plasma exposure of nateglinide and its metabolite M1 decreased significantly after oral administration of nateglinide to rats with diabetes induced by a combination of high-fat diet and low-dose STZ.

Several drug transporters including oligopeptide transporters (PEPTs), breast cancer resistance protein (BCRP), organic cation transporters (OCTs), organic anion-transporting polypeptides (OATPs), and P-glycoprotein (P-GP) have been identified to account for the intestinal absorption of drugs (Estudante et al., 2013). Monocarboxylate transporters (MCTs/SLC16A) have been identified as transporting monocarboxylic acids, which are also associated with several diseases such as atherosclerosis, cancer, mental retardation, and cataract formation (Bonen, 2000; Bonen et al., 2006; Jones et al., 2017). MCT6 (SLC16A5), a unique member in MCTs family, has been demonstrated to transport nateglinide, probenecid, and several diuretics (such as bumetanide, azosemide, and furosemide) but not typical substrates for MCTs such as L-lactic acid (Murakami et al., 2005; Kohyama et al., 2013). Furthermore, the intestinal protein and mRNA levels of MCT6 are highly expressed (Murakami et al., 2005; Jones et al., 2017). These findings imply that MCT6 is probably responsible for the intestinal absorption of nateglinide and that the decreased oral plasma exposure of nateglinide under diabetic states may partly be attributed to alterations in expression and function of intestinal MCT6.

Short-chain fatty acids (SCFA) mainly including butyrate, propionate, and acetate, are produced by the gut flora in intestine as fermentation products from undigested or unabsorbed food ingredients (Bergman, 1990; Rios-Covian et al., 2016). Accumulating evidence has demonstrated their versatile healthy effects in humans, including as metabolic fuel for the intestinal epithelium (Macfarlane and Macfarlane, 2012; Jung et al., 2015), improvement in the intestinal barrier and mucosa (Peng et al., 2009; Kelly et al., 2015), and antitumorigenesis and anti-inflammatory functions (Schwab et al., 2006; Louis et al., 2014; Keku et al., 2015). Interestingly, it was reported that butyrate could affect the function of the intestinal barrier via activating peroxisome proliferator-activated receptor $\gamma$ (PPAR $\gamma$ ) (Kinoshita et al., 2002; Peng et al., 2009) and altering the expression of transporters (Fukushima et al., 2009), including MCT1 and MCT4 (Ziegler et al., 2016). Several reports have shown that PPAR $\gamma$ is also involved in colon cell differentiation and colon cancer (Kliewer et al., 1995; Hamer et al., 2008).

The objective of our study was 1) to explore whether the decrease in oral plasma exposure of nateglinide under diabetic states results from the impairment of intestinal MCT6,2) to identify the contributions of MCT6 to the transport of nateglinide in human colorectal adenocarcinoma cell line Caco-2 using both the MCT6 inhibitor bumetanide and MCT6 knockdown with small interfering RNA (siRNA), 3) to document the role of SCFA, especially butyrate, in the alteration of intestinal MCT6 using Caco-2 cells (which was further confirmed using in vivo data), and 4) to explore whether the alterations in expression and function of MCT6 by SCFA are involved in PPAR $\gamma$, using both a PPAR $\gamma$ antagonist and PPAR $\gamma$ knockdown with siRNA in Caco-2 cells.

\section{Materials and Methods}

Reagents. M1 was a gift from the laboratory of Jiang Cheng (College of Pharmacy, China Pharmaceutical University). Nateglinide, bumetanide, phenacetin, and verapamil were purchased from Meilun Biologic Technology (Dalian, People's Republic of China). Ko143 (tert-butyl 3-[(2S,5S,8S)-14-methoxy-2-(2methylpropyl)-4,7-dioxo-3,6,17-triazatetracyclo[8.7.0.0 $\left.0^{3,8} \cdot 0^{11,16}\right]$ heptadeca1(10),11,13,15-tetraen-5-yl]propanoate), troglitazone, and 2-chloro-5-nitro- $\mathrm{N}$ phenylbenzamide (GW9962) were obtained from MedChem Express (Monmouth Junction, NJ). Glucose-6-phosphate dehydrogenase (G-6PDH), STZ, glycylsarcosine (Gly-Sar), $\beta$-NADP ${ }^{+}$, ketoconazole, and D-glucose-6-phosphate (G-6-P) were from Sigma-Aldrich (St. Louis, MO). Naringin was obtained from TCI (Tokyo, Japan). Tetraethylammonium and L-lactic acid were obtained from Mecklin Biochemical (Shanghai, People's Republic of China). The BCA kit and RIPA lysis buffer were from Beyotime Biotechnology (Nanjing, People's Republic of China). All other biologic reagents or chemicals were of highest grade commercially available.

Animals. Male Sprague-Dawley rats (Super-B\&K Laboratory Animal Co., Ltd., Shanghai, People's Republic of China) were kept in an environment with controlled relative humidity $(50 \% \pm 5 \%)$ and temperature $\left(24 \pm 2{ }^{\circ} \mathrm{C}\right)$ with 12-hour light-dark cycles; both water and common chow were freely available. All studies were conducted according to the Guide for the Care and Use of Laboratory Animals (National Institutes of Health) guidelines and were approved by the China Pharmaceutical University Animal Ethics Committee. (No. 1621010273).

Induction of Diabetic Rats. The diabetic rats were induced according to a protocol previously described elsewhere (Shu et al., 2016a). Briefly, male rats, weighing about $100 \mathrm{~g}$, were divided randomly into diabetic (DM), high-fat diet (HFD), and control (CON) rats. The diet for CON rats was common chow; the diet for both DM and HFD rats was a high-fat diet (TROPHIC Animal Feed Co., Nantong, People's Republic of China) consisting of $13 \%$ lard, $2 \%$ sesame oil, $20 \%$ sucrose, $3 \%$ cholesterol, $5 \%$ peanuts, $0.1 \%$ sodium cholate, and $57 \%$ normal chow. After 6 weeks of feeding, STZ ( $35 \mathrm{mg} / \mathrm{kg}$, dissolved in citrate buffer, $\mathrm{pH}$ 4.5) was intraperitoneally injected into the DM rats; both the CON and HFD rats were injected with vehicle. On day 7 after the STZ injection, diabetes development was confirmed by measuring the fasting glucose in blood (FBG) using a glucose assay kit (Jiancheng Bioengineering Institute, Nanjing, People's Republic of China). A successful FBG in DM rats was higher than $11 \mathrm{mM}$. Afterward the rats were maintained on their diets for another 3 weeks for the following experiments.

Pharmacokinetics of Nateglinide in Rats. The pharmacokinetics of nateglinide in DM, HFD, and CON rats $(n=6)$ after oral administration of nateglinide were investigated. Briefly, the experimental rats were fasted overnight, then $0.25 \mathrm{ml}$ of blood was collected for assessment of the biochemical parameters; nateglinide was then orally administrated $(10 \mathrm{mg} / \mathrm{kg}$, suspended in 0.25\% CMC-Na). At 2, 5, 10, 15, 20, 30, 45, 60, 90, 120, 240, and 480 minutes after administration, under diethyl ether anesthesia, about $0.25 \mathrm{ml}$ of blood was sampled from the oculi chorioideae vein and collected into heparinized tubes. After each four samplings, the experimental rats received a suitable amount of normal saline via the tail vein to compensate for the blood loss.

On next day (day 22 after the STZ injection), after overnight fasting the animals were sacrificed under diethyl ether anesthesia. The intestine and liver were obtained for measurement of mRNA or protein and preparation of rat hepatic microsomes, respectively. The levels of total triglyceride (TG), total cholesterol (TC), and FBG were detected by assay kits (Jiancheng Bioengineering Institute). The fasting insulin (FINS) was detected by radioimmunoassay insulin kit (North Institute of Biotechnology, Beijing, People's Republic of China). HOMA-IR (homeostatic model assessment insulin resistance) was calculated according to the equation HOMA-IR $=$ FGB $(\mathrm{mM}) \times$ FINS $(\mathrm{mU} / \mathrm{l}) / 22.5$. The contents of the small intestine were also washed out with $1 \mathrm{ml}$ of $0.9 \%$ saline for determining the SCFA (butyrate, propionate, and acetate) after derivatization by high-pressure liquid chromatography, as described elsewhere (Miwa, 2002).

Effect of MCT6 inhibitor bumetanide on the pharmacokinetics of nateglinide in rats was investigated. Briefly, six normal male rats (about $260 \mathrm{~g}$ ) orally received nateglinide $(10 \mathrm{mg} / \mathrm{kg})$ alone; another six male rats were orally coadministrated with nateglinide $(10 \mathrm{mg} / \mathrm{kg})$ and bumetanide $(10 \mathrm{mg} / \mathrm{kg})$. Blood samples were obtained as described earlier. 
The effect of butyrate on the pharmacokinetics of nateglinide in rats was also investigated as previously reported elsewhere (Lucas et al., 2018). Briefly, six normal male rats drank water containing butyrate $(150 \mathrm{mM})$ for 4 weeks, and another six rats drank normal water. Then the rats were orally administered nateglinide $(10 \mathrm{mg} / \mathrm{kg})$. The samples of blood were obtained as described previously.

Plasma samples were immediately obtained by centrifugation, and the concentrations of nateglinide and M1 in plasma were determined by liquid chromatography with mass spectrometry (LC-MS). The pharmacokinetic parameters for individual rats were assessed via Phoenix WinNonlin 7.0 (Pharsight, St. Louis, MO) using noncompartmental analysis.

Nateglinide Metabolism in Hepatic Microsomes of Rats. Rat hepatic microsomes were prepared as previously reported elsewhere (Hu et al., 2011). In hepatic microsomes, nateglinide metabolism was documented using M1 formation and nateglinide depletion (Takanohashi et al., 2007). After the preincubation of nateglinide (final level $2 \mu \mathrm{M}$ ) and microsomes $\left(1 \mathrm{mg} / \mathrm{ml}\right.$ ) for 5 minutes at $37^{\circ} \mathrm{C}$, the reaction was initiated by adding a NADPH-regenerating system $(1 \mathrm{U} / \mathrm{ml}$ G-6PDH, $10 \mathrm{mM}$ G-6-P, $0.5 \mathrm{mM} \beta$-NADP ${ }^{+}$, and $5 \mathrm{mM} \mathrm{MgCl}_{2}$ dissolved in $0.1 \mathrm{M}$ PBS, pH 7.4) and was terminated by adding $40 \mu \mathrm{l}$ of $\mathrm{HCl}(1 \mathrm{M})$ at $0,2,5,10,15$, 20,30, and 40 minutes, respectively. Nateglinide metabolism in the microsomes of $\mathrm{CON}$ rats was also examined in the presence of the CYP3A inhibitor ketoconazole $(1 \mu \mathrm{M})$. The amount of remaining nateglinide and $\mathrm{M} 1$ formation were simultaneously measured. The intrinsic clearance $\left(\mathrm{CL}_{\mathrm{int}}\right)$ of nateglinide depletion was calculated as $\mathrm{CL}_{\text {int }}=k / C_{\text {mic }}$, where $C_{\text {mic }}$ was the level of microsomal protein. The elimination constant obtained by the curve was $k$, the logarithm of the remaining amount of nateglinide versus incubation time, via linear regression of the least square.

Intestinal Absorption of Nateglinide in Rats. Nateglinide absorption in intestinal of rats was evaluated using single-pass intestinal perfusion (SPIP), as previously described elsewhere (Zhong et al., 2016). Briefly, after the animals were fasted overnight, pentobarbital sodium $(45 \mathrm{mg} / \mathrm{kg})$ was intraperitoneally injected into the DM, HFD, and CON rats $(n=6)$. An isolated jejunum $(\sim 10 \mathrm{~cm})$ was fixed with the constant flow pump (flow speed $0.2 \mathrm{ml} / \mathrm{min}, \mathrm{Q}$ ) to input perfusion buffer. After 5 minutes of preperfusion with blank perfusion buffer, the segment of jejunum was perfused with perfusion buffer containing nateglinide $(10 \mu \mathrm{M})$ for 15 minutes to achieve stability. In the next 2 hours, consecutive output solutions were collected through the cannula inserted into the distal segment of isolated jejunum per 15 minutes. On completion of the perfusion, the rats were sacrificed, and the length and width of the perfused jejunum (A, length $\times$ width) were measured.

The blank perfusion buffer ( $\mathrm{pH} 6.5$ ) contained $\mathrm{NaH}_{2} \mathrm{PO}_{4}(43 \mathrm{mM})$, D-glucose $(10 \mathrm{mM})$, mannitol $(35 \mathrm{mM}), \mathrm{Na}_{2} \mathrm{HPO}_{4}(28 \mathrm{mM}), \mathrm{NaCl}(48 \mathrm{mM})$, and $\mathrm{KCl}$ (5.4 mM). All solutions were kept in a $37^{\circ} \mathrm{C}$ water bath, and the animals' body temperature was kept in $37^{\circ} \mathrm{C}$ by electric blanket. The drug concentrations in the input and output solutions $\left(C_{\text {in }}\right.$ and $\left.C_{\text {out }}\right)$ were measured by LC-MS. The apparent effective permeability $\left(\mathrm{P}_{\mathrm{eff}}\right)$ was obtained using equation $\mathrm{P}_{\mathrm{eff}}=-\mathrm{Q} \times \ln$ $\left(\mathrm{C}_{\text {out }} / \mathrm{C}_{\text {in }}\right) / \mathrm{A}$. And $C_{\text {out }}$ was corrected using a weight calibration method (Sutton et al., 2001).

The effects of Gly-Sar (PEPT1 inhibitor) and bumetanide (MCT6 inhibitor) on the intestinal absorption of nateglinide were investigated in normal rats. Briefly, the isolated jejunum was perfused with perfusion buffer containing nateglinide alone $(5 \mu \mathrm{M})$ or combined with Gly-Sar $(25 \mathrm{mM})$ or bumetanide $(250 \mu \mathrm{M})$. The concentrations of the inhibitors were derived from previous reports (Murakami et al., 2005; Jappar et al., 2010; Posada and Smith, 2013). The $\mathrm{P}_{\text {eff }}$ values in the presence of transporter inhibitors were calculated.

Another group of DM rats was established to investigate the function of intestinal MCT6. In brief, the intestinal absorption of MCT6 substrate bumetanide and its $\mathrm{P}_{\mathrm{eff}}$ values were determined via perfusion with perfusion buffer containing bumetanide $(5 \mu \mathrm{M})$ as described earlier.

Cell Culture and Drug Uptake. Caco-2 cells, a human colorectal adenocarcinoma cell line (Cell Bank of the Chinese Academy of Science, Shanghai, China), were kept in $5 \% \mathrm{CO}_{2}$ at $37^{\circ} \mathrm{C}$ and cultured in Dulbecco's modified Eagle's medium consisting of 10\% FBS (GIBCO/ThermoFisher, Grand Island, NY), streptomycin $(100 \mu \mathrm{g} / \mathrm{ml})$, L-glutamine $(2 \mathrm{mM})$, penicillin (100 IU/ml), $\mathrm{NaHCO}_{3}(3.7 \mathrm{~g} / \mathrm{l})$, and nonessential amino acids. The medium was renewed every 2 days. When $80 \%$ confluent, the cells were subcultured and seeded in 24 -well plates at $1.5 \times 10^{5}$ per well. The seeded cells continued culturing for 7 days, when a significant fraction of the cell population exhibited a colonic phenotype, then the uptake study was performed as previously described elsewhere (Kimura et al., 2009; Tsukagoshi et al., 2014; Kimura et al., 2017).

Briefly, after removing the culture medium, the Caco- 2 cells were washed with $37^{\circ} \mathrm{C}$ Hanks' balanced salt solution (HBSS, $1 \mathrm{mM}$, pH 6.5) 2 times. Uptake was started via addition of $500 \mu \mathrm{l}$ of $\operatorname{HBSS}\left(37^{\circ} \mathrm{C}\right)$ containing nateglinide $(10 \mu \mathrm{M})$ with or without transporter inhibitors (Gly-Sar [25 mM] for PEPT1, verapamil [100 $\mu \mathrm{M}]$ for P-GP, Ko143 [25 $\mu \mathrm{M}]$ for BCRP, naringin [200 $\mu \mathrm{M}]$ for OATP1A2, tetraethylammonium [5 mM] for OCTs, L-lactic acid [15 mM] for MCT1-4, and bumetanide [250 $\mu \mathrm{M}$ ] for MCT6) and terminated by washing with ice-cold HBSS 3 times after 1 hour of incubation. The concentrations of relevant inhibitors were derived from previous studies (Okamura et al., 2002; Murakami et al., 2005; Ogihara et al., 2009; Posada and Smith, 2013; Jouan et al., 2014; Wen et al., 2015; Zhang et al., 2018). The intracellular concentration of nateglinide was determined by LC-MS.

Effect of SCFA on MCT6 function in Caco-2 cells was further measured using the uptake of MCT6 substrate bumetanide. In brief, 5 days after cell seeding, the cells continued culturing for another 2 days with a culture medium containing butyrate $(1 \mathrm{mM})$, propionate $(1 \mathrm{mM})$, acetate $(10 \mathrm{mM})$, or their mixture, respectively. Then the bumetanide $(50 \mu \mathrm{M})$ uptake was measured. The levels of SCFA were determined as previously described elsewhere (Cummings et al., 1987; Fukushima et al., 2009), and the proportions were based on the data measured in this study. The concentration-dependent effects of butyrate on the function of MCT6 were also investigated in Caco- 2 cells after 48 hours of incubation with culture medium containing various levels of butyrate $(0,0.01,0.1$, and $1 \mathrm{mM}$ ).

The role of PPAR $\gamma$ in the altered function of MCT6 was also documented in Caco- 2 cells cultured with a medium containing butyrate $(1 \mathrm{mM}), \operatorname{PPAR} \gamma$ agonist troglitazone $(5 \mu \mathrm{M})$, butyrate $(1 \mathrm{mM})+$ PPAR $\gamma$ antagonist GW9662 $(5 \mu \mathrm{M})$, or troglitazone $(5 \mu \mathrm{M})+$ GW9662 $(5 \mu \mathrm{M})$ for 48 hours. The concentrations of agonist and antagonist were derived from previous studies (Wachtershauser et al., 2000; Ulrich et al., 2005; Marion-Letellier et al., 2008).

MCT6 or PPAR $\gamma$ Knockdown with siRNA in Caco-2 Cells. To further estimate the contributions of MCT6 to transport of nateglinide and bumetanide, MCT6 knockdown in Caco-2 cells used Lipofectamine 3000 (Invitrogen, Carlsbad, CA) with MCT6 siRNA (120 nM) (Slc16a5: 5'-CCAUCAUCGGCUUCAGCAAdTdT-3' and 5'-UUGCUGAAGCCGAUGAUGGdTdT-3'), which was designed by GenePharma Technology (Shanghai, People's Republic of China), according to the manufacturer's instructions. After 3 days, the expression of MCT6 protein was evaluated by Western blot, and an uptake assay of nateglinide $(10 \mu \mathrm{M})$ and bumetanide $(50 \mu \mathrm{M})$ was performed. The intracellular concentrations of nateglinide and bumetanide were measured by LC-MS.

To identify whether PPAR $\gamma$ participated in the expression of MCT6, PPAR $\gamma$ knockdown in Caco-2 cells was also performed using PPAR $\gamma \operatorname{siRNA}(120 \mathrm{nM})$ (PPARg: 5'-CCAAGUUUGAGUUUGCUGUdTdT-3' and 5'-ACAGCAAACUCAAACUUGGdTdT-3') (GenePharma) (Vara et al., 2013). After 24 hours, the cells continued culturing for another 48 hours with a culture medium containing butyrate $(1 \mathrm{mM})$ or troglitazone $(5 \mu \mathrm{M})$. Then Western blot analysis was conducted to estimate the expressions of PPAR $\gamma$ and MCT6 protein.

Quantitative Real-Time Polymerase Chain Reaction. Expressions of mRNA including hepatic Cyp2c11v1 (CYP2C11), intestinal Slc15a1 (PEPT1), Slc15a2 (PEPT2), Slco1a5 (OATP1A5), Slc16a1 (MCT1), Slc16a5 (MCT6), Slc16a6 (MCT7) and Slc16a10 (MCT10) in experimental rats were determined by quantitative real-time polymerase chain reaction (qRT-PCR). The total mRNA was extracted by TriPure (Aidlab Biotechnology, Beijing, People's Republic of China) according to the manufacturer's instructions. ReverTra Ace Master Mix with gDNA Remover (TOYOBO, Osaka, Japan) was used for cDNA synthesis by Eppendorf Mastercycler Nexus (Hamburg, Germany).

The qRT-PCR primers were designed by Oligo 7.0 (Molecular Biology Insights, Colorado Springs, CO) or obtained from PrimerBank following NCBI Blast. The sequences of the primers are shown in Supplemental Table 1. The qRTPCR was performed with a Roche Lightcycler 96 (Roche, Penzberg, Germany) using Thunderbird SYBR Mix (TOYOBO). The protocol was preincubation for 60 seconds at $95^{\circ} \mathrm{C}$, three-step amplification $\left(10\right.$ seconds at $95^{\circ} \mathrm{C}, 30$ seconds at $60^{\circ} \mathrm{C}, 30$ seconds at $\left.72^{\circ} \mathrm{C}\right)$, melting $\left(10\right.$ seconds at $95^{\circ} \mathrm{C}, 60$ seconds at $65^{\circ} \mathrm{C}$, 1 second at $97^{\circ} \mathrm{C}$ ), then cooling 30 seconds at $37^{\circ} \mathrm{C}$. The mRNA levels of the target gene were corrected by $\beta$-actin according to $2^{-\Delta \Delta \mathrm{Ct}}$ method (Livak and Schmittgen, 2001). 
Western Blot. The protein of tissue and cells was extracted by radioimmunoprecipitation assay (RIPA) lysis buffer containing phenylmethylsulfonyl fluoride $(1 \mathrm{mM})$ and measured by BCA assay kit. After separating by SDS-PAGE, protein $(\sim 20 \mu \mathrm{g})$ was transferred to polyvinylidene fluoride membranes (Millipore, Billerica, MA) and then blocked at $4^{\circ} \mathrm{C}$ overnight in Tris-buffered saline $(10 \mathrm{mM})$ containing $5 \%$ nonfat milk and $0.1 \%$ Tween 20 . The given primary antibodies against PEPT1 (dilution 1:500), PPAR $\gamma$ (dilution 1:200) (Santa Cruz Biotechnology, Dallas, TX), MCT6 (dilution 1:500) (ThermoFisher Scientific), and $\beta$-actin (dilution 1:2500) (Bioworld Technology, St. Louis Park, $\mathrm{MN}$ ) were incubated with membranes at $4^{\circ} \mathrm{C}$ for 8 hours, respectively. Afterward, a horseradish peroxidase-conjugated secondary antibody (dilution 1:5000) (Bioworld Technology) was incubated with the membranes for 2 hours. The immunoreactivity was detected by Tanon 5200 Multi Chemiluminescent System (Shanghai, People's Republic of China) using Super Signal WestFemto Chemiluminescent Substrate (ThermoFisher Scientific). All protein levels were normalized to $\beta$-action.

Drug Analysis. The concentrations of nateglinide and bumetanide were measured by LC-MS. Briefly, $20 \mu \mathrm{HCl}(1 \mathrm{M}), 1 \mathrm{ml}$ ethyl acetate and $10 \mu \mathrm{l}$ phenacetin $(200 \mathrm{ng} / \mathrm{ml}$, internal standard) were added into $100 \mu \mathrm{l}$ samples. After mixing rapidly and centrifuging, $800 \mu \mathrm{l}$ supernatant was volatilized to dryness by nitrogen gas. The sediment was dissolved in a $100-\mu 1$ mixture $(60 \%$ acetonitrile $/ 40 \%$ water) and centrifuged again. Two microliters of supernatant was analyzed by Shimadzu LC-MS 2020 System (Kyoto, Japan) using a Shimadzu VP-ODS C18 column $(4.6 \mu \mathrm{m}, 250 \times 2.0 \mathrm{~mm})$. The mobile phase was a mixture of acetonitrile (A) and water containing $0.1 \%$ formic acid (B) at a constant flow rate $(0.2 \mathrm{ml} / \mathrm{min})$.

The gradient separation for nateglinide and M1 was initial wash of $36 \% \mathrm{~A}$ and increased linearly to $68 \%$ at 7.5 minutes, then reduced back to $36 \%$ at 15 minutes until finishing analysis. For bumetanide, the proportion of mobile phase A was kept at $43 \%$ using isocratic elution. The analytes $[\mathrm{M}+\mathrm{H}]^{+}$were measured at $\mathrm{m} / \mathrm{z}$ 318.2 for nateglinide, $\mathrm{m} / \mathrm{z}, 365.3$ for bumetanide, $\mathrm{m} / \mathrm{z} 334.1$ for M1, and $\mathrm{m} / \mathrm{z} 180.1$ for phenacetin.

For nateglinide, the linear range was $0.0031-8 \mu \mathrm{g} / \mathrm{ml}$ in plasma, $0.31-20 \mu \mathrm{M}$ in microsomes and perfusion buffer, and $0.039-2.5 \mu \mathrm{M}$ in cells. For M1, the linear range was $0.0016-4 \mu \mathrm{g} / \mathrm{ml}$ and $0.156-10 \mu \mathrm{M}$ in plasma and microsomes, respectively. For bumetanide, the linear range was $0.156-10$ and $0.019-1.25 \mu \mathrm{M}$ in perfusion buffer and cells, respectively. The lower relative S.D. (less than $10 \%$ ) was detected both interday and intraday. The recoveries of all analytes were larger than $95 \%$.

Statistical Analysis. All values are illustrated as mean \pm S.D. One-way ANOVA was used to calculate the statistical variations among groups followed by Tukey's post hoc test. $P<0.05$ was considered statistically significant.

\section{Results}

Induction of Diabetic Rats. Physiologic and biochemical parameters were determined on day 21 after the injection of STZ (Table 1).
Although significant difference was FINS was similar to significant difference was CON rats, significant difference was DM rats showed several typical diabetic characteristics including polyuria, polydipsia, polyphagia, and a significant increase in liver weight and in levels of FGB, TC, TG as well as HOMA-IR, which reflected the disease characteristics and the natural history of type II diabetes.

The SCFA levels in the small intestinal content of the three groups were also measured. Although large individual difference existed, an increased amount of SCFA, especially butyrate, was obviously found in the small intestinal content of DM rats. The order was DM rats $>$ HFD rats $>\mathrm{CON}$ rats. Acetate showed the highest amount; the proportion of acetate/propionate/butyrate in CON rats was measured as 36:2:1.

Pharmacokinetics of Nateglinide in Rats. After oral administration of nateglinide, the plasma concentrations of nateglinide and its metabolite M1 in DM, HFD, and CON rats were determined (Fig. 1, $\mathrm{A}$ and $\mathrm{B}$ ). We found that the plasma exposure of nateglinide in DM rats was prominently lower than in $\mathrm{CON}$ rats. The corresponding parameters for the pharmacokinetics were also calculated (Table 2). The area under curve (AUC) and peak concentrations $\left(C_{\max }\right)$ in DM rats were only $28.2 \%$ and $16.9 \%$ of CON rats, respectively, although diabetes did not affect its half-life. Lower plasma concentrations of M1 were also found correspondingly in DM rats, leading to decreases in the $C_{\max }$ and AUC values of M1 by $80.7 \%$ and $61.8 \%$, respectively, compared with the CON rats. HFD feeding also significantly decreased the plasma exposure of M1, but only a decreased trend was found in the plasma concentrations of nateglinide.

Coadministration of MCT6 inhibitor bumetanide also remarkably decreased oral plasma concentrations of nateglinide and M1 in normal rats (Fig. 1, C and D). The AUC and $\mathrm{C}_{\max }$ values of nateglinide were only about one third of nateglinide alone. The $\mathrm{C}_{\max }$ and AUC values of M1 were also only about $40 \%$ of nateglinide alone (Table 2).

Metabolism of Nateglinide in Hepatic Microsomes of Rats. In hepatic microsomes, we investigated nateglinide metabolism via M1 formation and nateglinide depletion (Supplemental Fig. 1, A and B). We found that the contribution of M1 formation to nateglinide depletion after 40 minutes of incubation in $\mathrm{CON}$ rats was $77.2 \%$, indicating that M1 was the main metabolite of nateglinide. The addition of the CYP3A inhibitor ketoconazole $(1 \mu \mathrm{M})$ significantly decreased the M1 formation and the $\mathrm{CL}_{\text {int }}$ values of nateglinide by about $24 \%$ and $40 \%$ (Supplemental Fig. 1, D and F), respectively, implying that CYP3A is also involved in nateglinide metabolism, including M1

TABLE 1

Physiologic and biochemical parameters of DM, HFD, and CON rats

Data are presented as mean \pm S.D. $(\mathrm{n}=6)$.

\begin{tabular}{lccc}
\hline \multicolumn{1}{c}{ Parameters } & CON & HFD & DM \\
\hline Body weight $(\mathrm{g})$ & $297 \pm 13$ & $304 \pm 12$ & $250 \pm 14^{a, b}$ \\
Liver weight (\% of body weight) & $2.63 \pm 0.27$ & $5.38 \pm 0.43^{a}$ & $8.16 \pm 0.62^{a, b}$ \\
FGB (mM) & $5.80 \pm 0.53$ & $5.81 \pm 0.44$ & $22.7 \pm 1.8^{a, b}$ \\
FINS (mIU/l) & $46.5 \pm 9.2$ & $49.7 \pm 11.2$ & $44.4 \pm 5.1$ \\
HOMA-IR & $12.1 \pm 2.8$ & $12.9 \pm 2.7$ & $44.6 \pm 6.5^{a, b}$ \\
TC (mM) & $1.70 \pm 0.23$ & $4.51 \pm 1.23^{a}$ & $14.1 \pm 3.1^{a, b}$ \\
TG (mM) & $0.547 \pm 0.109$ & $0.828 \pm 0.195^{a}$ & $4.41 \pm 1.48^{a, b}$ \\
Acetate $(\mathrm{mM})^{c}$ & $1.31 \pm 0.59$ & $3.57 \pm 1.75^{d}$ & $5.20 \pm 1.65^{a}$ \\
Propionate $(\mu \mathrm{M})^{c}$ & $85.3 \pm 50.1$ & $378 \pm 212^{d}$ & $538 \pm 383^{d}$ \\
Butyrate $(\mu \mathrm{M})^{c}$ & $36.5 \pm 12.3$ & $150 \pm 93^{d}$ & $477 \pm 251^{a, e}$ \\
\hline
\end{tabular}

CON, normal diet rats; DM, diabetic rats; FBG, fasting glucose in blood; FINS, fasting insulin level; HFD, high-fat diet rats; HOMA-IR, homeostasis model assessment insulin resistance; TC, total cholesterol level; TG, triglyceride level.

${ }^{a} P<0.01$ vs. CON.

${ }^{b} P<0.01$ vs. HFD.

${ }^{c}$ Intestinal content in small intestine was washed using $1 \mathrm{ml}$ normal saline, and the concentration of the washed solution was measured

by high-pressure liquid chromatography.

${ }^{d} P<0.05$ vs. CON

${ }^{e} P<0.05$ vs. HFD. 

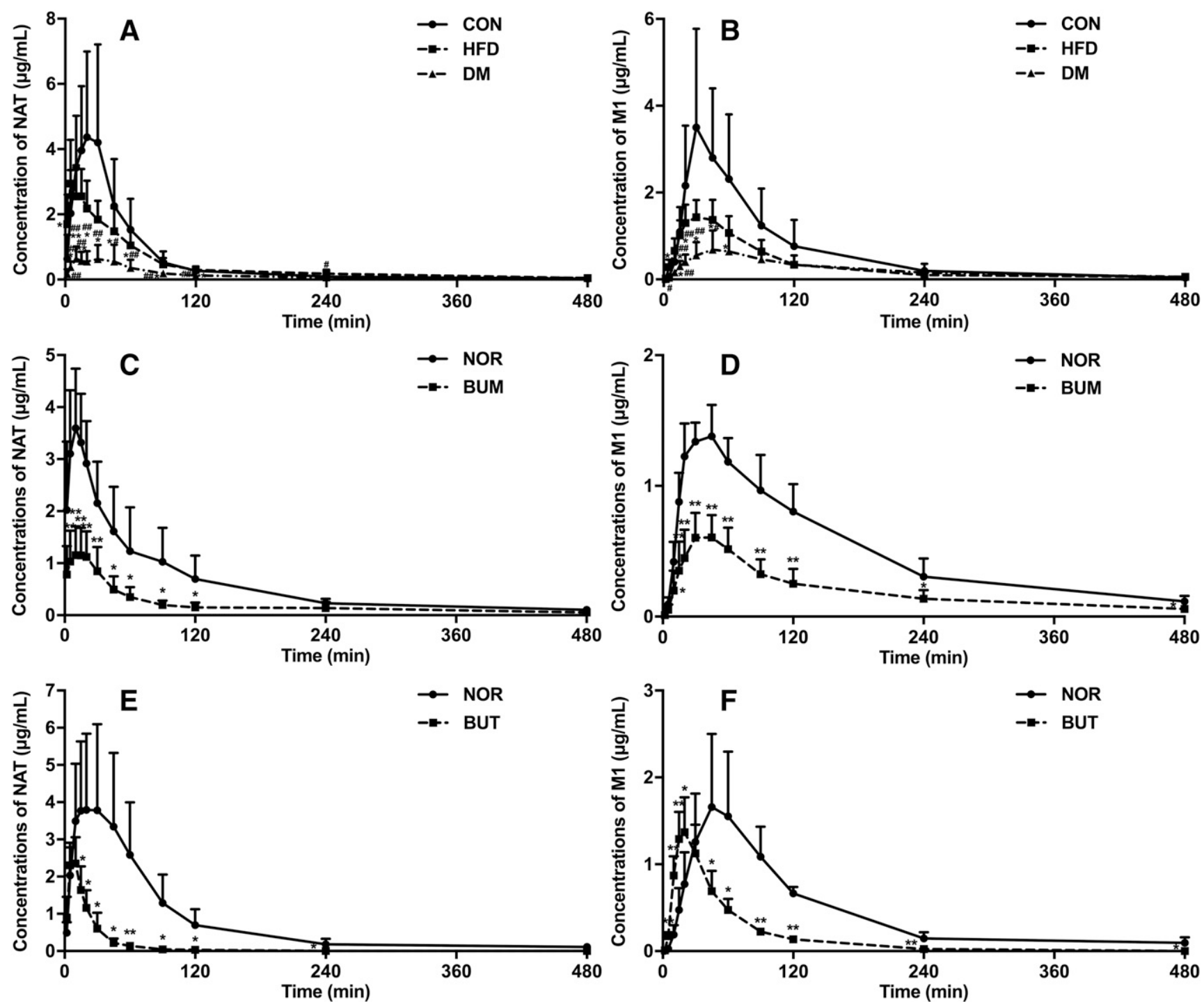

Fig. 1. Pharmacokinetic profiles of nateglinide (NAT) and its metabolite M1 in rats. Plasma concentrations of nateglinide (A) and M1 (B) after oral administration of nateglinide $(10 \mathrm{mg} / \mathrm{kg})$ to CON, HFD, and DM rats. Plasma concentrations of nateglinide (C) and M1 (D) after oral administration of nateglinide (10 mg/kg, NOR) alone or coadministration with bumetanide $(10 \mathrm{mg} / \mathrm{kg}, \mathrm{BUM})$ to normal rats. Plasma concentrations of nateglinide (E) and M1 (F) after oral administration of nateglinide (10 mg/kg) to rats drinking normal water (NOR) and rats drinking water containing butyrate $(150 \mathrm{mM}, \mathrm{BUT})$ for 4 weeks. Data are presented as mean \pm S.D. $(n=6)$. $* P<0.05$; $* * P<$ 0.01 vs. CON or NOR; ${ }^{\#} P<0.05 ;{ }^{\# \#} P<0.01$ vs. HFD

formation. Importantly, the $\mathrm{CL}_{\text {int }}$ values of nateglinide were comparable in the hepatic microsomes of DM, HFD, and CON rats (Supplemental Fig. 1A), although M1 formation in DM rats was prominently lower compared with the $\mathrm{CON}$ rats; the decrease (by about 23\%) in M1 formation was also less than that in mRNA expression of CYP2C11 (by about 84\%) (Supplemental Fig. 1C).

Intestinal Absorption of Nateglinide and Expression of Intestinal Drug Transporters Related to Nateglinide Transport in Rats. The intestinal absorption of nateglinide was documented using SPIP in DM, HFD, and CON rats. The intestinal absorption of nateglinide was remarkably reduced in DM rats (Supplemental Fig. 2A), whose $P_{\text {eff }}$ values were only about $60 \%$ those of the CON rats (Fig. 2A). Although low intestinal absorption of nateglinide was also found in HFD rats, its level of decrease was less than that in the DM rats (Supplemental Fig. 2A). Further study showed that the $\mathrm{P}_{\text {eff }}$ values during 120 minutes were positively correlated with the AUC values of nateglinide in DM, HFD, and CON rats (Fig. 2B).

The intestinal transporters related to nateglinide transport in DM, HFD, and CON rats were detected using qRT-PCR (Fig. 2C). The results indicated that both diabetes and HFD feeding significantly decreased the mRNA expression of Slc15a1 (PEPT1) and Slc16a5 (MCT6) in the intestine of rats. Diabetes also obviously decreased the intestinal mRNA level of Slco1a5 (OATP1A5).

The intestinal expressions of corresponding proteins were estimated using Western blot analysis (Fig. 2, D and E). In line with our findings for the expression of mRNA, both HFD feeding and diabetes significantly decreased the intestinal expressions of PEPT1 and MCT6 protein. The extent of the decrease in DM rats was larger than that in the HFD rats. The measured levels of PEPT1 protein in the DM and HFD rats were about $25 \%$ and $63 \%$ those of CON rats, respectively. Similarly, the levels of MCT6 protein in the DM and HFD rats decreased by about $81 \%$ and $41 \%$, respectively, compared with the CON rats. These results infer that the decreases in intestinal absorption of DM and HFD rats resulted from impaired intestinal expression and function of PEPT1 or MCT6.

The roles of MCT6 and PEPT1 in the intestinal absorption of nateglinide were documented using the MCT6 inhibitor bumetanide and PEPT1 inhibitor Gly-Sar, respectively (Fig. 2F; Supplemental Fig. 2B). We found that bumetanide, but not Gly-Sar, remarkably inhibited the 
TABLE 2

Pharmacokinetic parameters of nateglinide and M1 after oral administration of nateglinide $(10 \mathrm{mg} / \mathrm{kg})$

Data are presented as mean \pm S.D. $(n=6)$.

\begin{tabular}{|c|c|c|c|c|c|c|}
\hline & \multicolumn{3}{|c|}{ Nateglinide } & \multicolumn{3}{|c|}{ M1 } \\
\hline & $\mathrm{CON}$ & HFD & $\mathrm{DM}$ & $\mathrm{CON}$ & HFD & $\mathrm{DM}$ \\
\hline$C_{\max }(\mu \mathrm{g} / \mathrm{ml})$ & $4.77 \pm 2.46$ & $3.24 \pm 1.02$ & $0.805 \pm 0.449^{a}{ }^{b}$ & $3.68 \pm 2.34$ & $1.49 \pm 0.39^{c}$ & $0.709 \pm 0.422^{a}$, \\
\hline$T_{\max }(\min )$ & $19.3 \pm 9.3$ & $16.4 \pm 8.0$ & $27.9 \pm 13.8$ & $34.3 \pm 11.3$ & $32.9 \pm 9.1$ & $42.9 \pm 10.4$ \\
\hline AUC $(\min \bullet \mu \mathrm{g} / \mathrm{ml})$ & $244 \pm 111$ & $179 \pm 56$ & $69.0 \pm 41.6^{a b},^{b}$ & $304 \pm 153$ & $144 \pm 39^{c}$ & $116 \pm 50^{c}$ \\
\hline$T_{1 / 2}(\min )$ & $64.8 \pm 31.6$ & $55.8 \pm 44.7$ & $73.7 \pm 38.4$ & $86.9 \pm 39.8$ & $47.9 \pm 18.6^{c}$ & $138 \pm 102$ \\
\hline \multirow[t]{2}{*}{ MRT (min) } & $69.3 \pm 31.0$ & $73.2 \pm 21.1$ & $112 \pm 43$ & $108 \pm 47$ & $92.2 \pm 21.7$ & $204 \pm 137$ \\
\hline & NOR & BUM & & NOR & BUM & \\
\hline$C_{\max }(\mu \mathrm{g} / \mathrm{ml})$ & $3.79 \pm 1.12$ & $1.30 \pm 0.54^{a}$ & & $1.46 \pm 0.19$ & $0.645 \pm 0.179^{a}$ & \\
\hline$T_{\max }(\min )$ & $10.0 \pm 4.1$ & $13.6 \pm 6.3$ & & $31.4 \pm 10.3$ & $38.6 \pm 11.8$ & \\
\hline AUC $(\min \bullet \mu \mathrm{g} / \mathrm{ml})$ & $301 \pm 93$ & $105 \pm 58^{a}$ & & $250 \pm 34$ & $105 \pm 37^{a}$ & \\
\hline$T_{1 / 2}(\min )$ & $111 \pm 40$ & $127 \pm 74$ & & $96.6 \pm 29.1$ & $128 \pm 57$ & \\
\hline \multirow[t]{2}{*}{ MRT (min) } & $136 \pm 47$ & $140 \pm 73$ & & $164 \pm 29$ & $192 \pm 58$ & \\
\hline & NOR & BUT & & NOR & BUT & \\
\hline$C_{\max }(\mu \mathrm{g} / \mathrm{ml})$ & $4.11 \pm 2.10$ & $2.52 \pm 0.63$ & & $1.67 \pm 0.83$ & $1.39 \pm 0.38$ & \\
\hline$T_{\max }(\min )$ & $19.2 \pm 6.7$ & $7.50 \pm 2.74^{a}$ & & $50.0 \pm 7.8$ & $18.3 \pm 2.6^{a}$ & \\
\hline AUC $(\min \bullet \mu \mathrm{g} / \mathrm{ml})$ & $380 \pm 122$ & $57.7 \pm 19.4^{a}$ & & $216 \pm 33$ & $79.2 \pm 18.1^{a}$ & \\
\hline$T_{1 / 2}(\min )$ & $66.4 \pm 45.7$ & $23.5 \pm 12.0$ & & $62.4 \pm 37.4$ & $41.3 \pm 8.9$ & \\
\hline MRT (min) & $110 \pm 59$ & $25.8 \pm 6.6^{a}$ & & $150 \pm 72$ & $68.2 \pm 7.0^{c}$ & \\
\hline
\end{tabular}

BUM, normal rats coadministrated with bumetanide (10 mg/kg); BUT, normal rats drinking water containing butyrate (150 mM) for 4 weeks; CON, normal diet rats; DM, diabetic rats; HFD, highfat diet rats; NOR, normal rats.

${ }^{a} P<0.01$ vs. $\mathrm{CON}$ or NOR

${ }^{b} P<0.01$ vs. HFD.

${ }^{c} P<0.05$ vs. $\mathrm{CON}$ or NOR

intestinal absorption of nateglinide, indicating that the intestinal absorption of nateglinide was mediated by intestinal MCT6 and that the decrease in the intestinal absorption of nateglinide resulted from down-regulation of intestinal MCT6 function by diabetes.

The function of intestinal MCT6 in DM rats was also assessed using another MCT6 substrate, bumetanide (Fig. 2G; Supplemental Fig. 2C). In accordance with the findings with nateglinide, diabetes and HFD feeding also significantly decreased the $\mathrm{P}_{\text {eff }}$ values of bumetanide, further demonstrating an impairment of intestinal MCT6 function in DM and HFD rats.

Roles of SCFA in Function and Expression of MCT6 in Caco-2 Cells. The effects of several transporter inhibitors, including Gly-Sar (for PEPT1), verapamil (for P-GP), Ko143 (for BCRP), naringin (for OATP1A2), tetraethylammonium (for OCTs), and L-lactic acid (for MCT1-4), or bumetanide (for MCT6), on the uptake of nateglinide were further investigated in Caco-2 cells (Fig. 3A). We found that only bumetanide significantly inhibited the uptake of nateglinide, further demonstrating that MCT6 might be involved in nateglinide transport.

The contributions of MCT6 to the transport of nateglinide were also identified in Caco-2 cells using MCT6 knockdown with siRNA, and bumetanide served as the MCT6 probe. Western blot analysis showed that the expression of MCT6 after transfection with siRNA was only about $19 \%$ that of the control cells, demonstrating successful silence of MCT6 (Fig. 3B). It was consistent with these findings for bumetanide (33.8\% of control cells) that MCT6 knockdown remarkably decreased the uptake of nateglinide ( $42.8 \%$ of control cells) (Fig. 3C). These results further indicated that MCT6 was probably the main transporter responsible for nateglinide uptake.

Our present study illuminated that diabetes extremely augmented the concentrations of SCFA, especially butyrate, in the small intestinal contents of rats (Table 1). Compared with the CON rats, the level of butyrate increased 13-fold in DM rats. The effects of SCFA including butyrate, propionate, acetate, and their mixture on MCT6 function in Caco- 2 cells were also documented using the uptake of bumetanide (Fig. 3D). The results showed that the butyrate and SCFA mixture remarkably decreased the uptake of bumetanide in Caco-2 cells, which was only
$59.0 \%$ and $51.7 \%$, respectively, that of the control cells. Propionate, but not acetate, only showed a slight inhibition on bumetanide uptake. These findings indicated that the inhibition of MCT6 function was mainly attributed to butyrate. Further study showed that butyrate decreased the expression and function of intestinal MCT6 in a concentration dependent manner (Fig. 3, E and F).

Involvement of PPAR $\gamma$ in Butyrate-Mediated MCT6 Downregulation in Caco-2 Cells. We investigated the involvement of PPAR $\gamma$ in butyrate-mediated MCT6 down-regulation in Caco-2 cells using both PPAR $\gamma$ antagonist GW9662 and PPAR $\gamma$ knockdown with siRNA. The results showed that the down-regulation of MCT6 expression and function by butyrate in Caco- 2 cells was remarkably reversed by GW9662 (Fig. 4, A and B). We also found that troglitazone down-regulated the expression and function of MCT6, which was also attenuated by GW9662. Moreover, butyrate concentration-dependently induced the expression of PPAR $\gamma$ (Fig. 4C).

All these results demonstrated that down-regulation of MCT6 expression and function by butyrate is involved in PPAR $\gamma$ activation. The role of PPAR $\gamma$ in butyrate-mediated MCT6 down-regulation was further confirmed using PPAR $\gamma$ knockdown with siRNA. Western blot analysis showed that the expression of PPAR $\gamma$ after transfection with siRNA was only about $27 \%$ that of control cells, demonstrating successful silencing of PPAR $\gamma$ (Fig. 4D). We also found that butyrate and troglitazone decreased the expression of MCT6 while they induced the expression of PPAR $\gamma$ in Caco- 2 cells transfected with negative control siRNA (Fig. 4, E and F). The alterations in expression of MCT6 and PPAR $\gamma$ by butyrate and troglitazone did not occur in Caco- 2 cells transfected with PPAR $\gamma$ siRNA.

Effect of Butyrate on Pharmacokinetics of Nateglinide in Rats. We investigated the pharmacokinetics of nateglinide after oral administration to rats in drinking water containing butyrate for 4 weeks to further confirm the role of butyrate in the function and expression of intestinal MCT6. Our results showed that butyrate treatment significantly decreased the plasma concentrations of nateglinide and M1 (Fig. 1, E and $\mathrm{F}$ ). The AUC values of nateglinide and M1 in rats drinking butyrate 

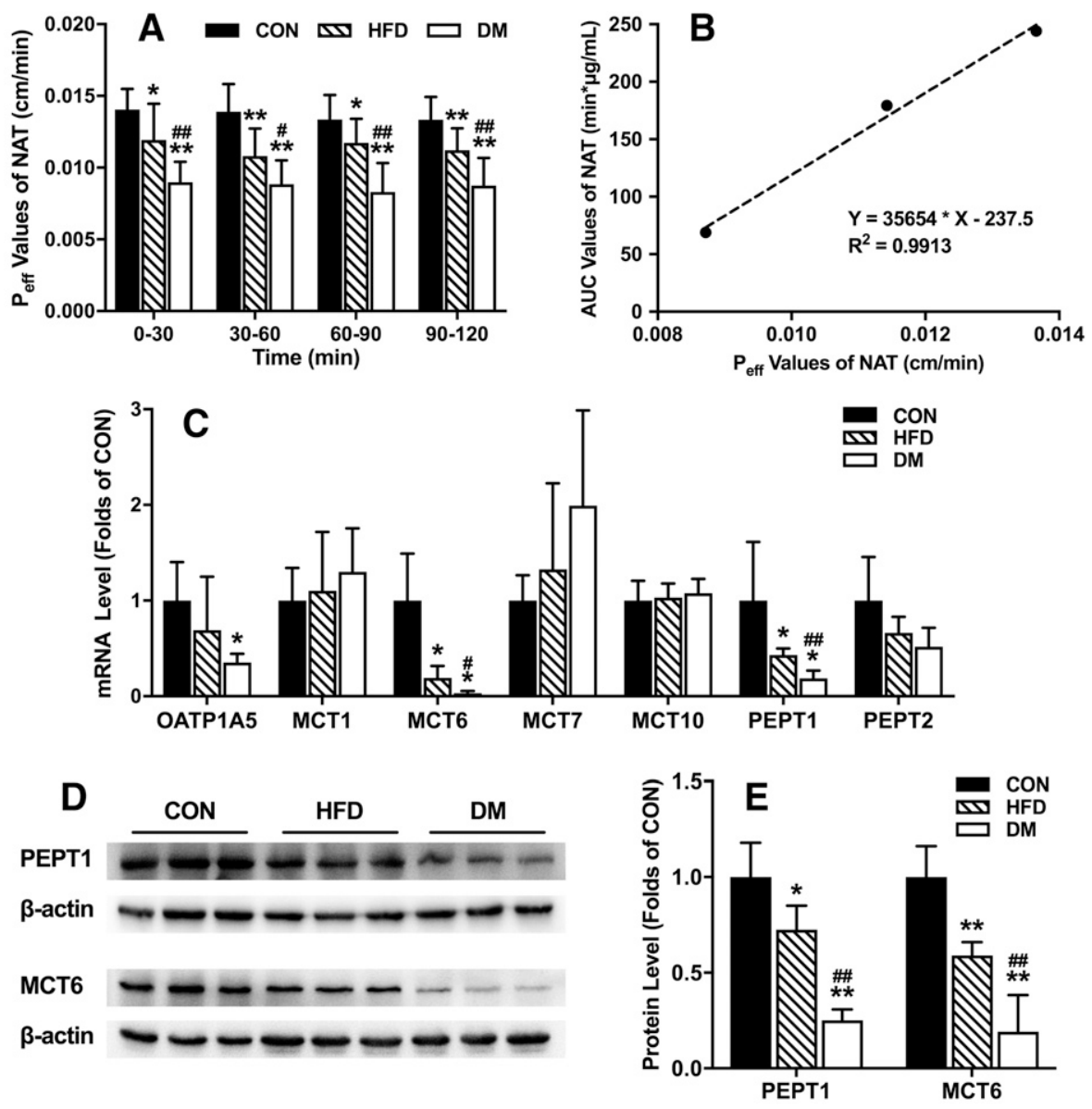

Fig. 2. Intestinal absorption of nateglinide (NAT) and relevant transporters. (A) $\mathrm{P}_{\text {eff }}$ values in the intestine of $\mathrm{DM}, \mathrm{HFD}$, and CON rats using SPIP with nateglinide $(10 \mu \mathrm{M})$. (B) Correlation analysis for $\mathrm{P}_{\mathrm{eff}}$ and AUC values of nateglinide in DM, HFD, and CON rats. (C) The mRNA levels of transporters related to intestinal absorption in DM, HFD, and CON rats. (D and E) Protein levels of PEPT1 and MCT6 in the intestine of DM, HFD, and CON rats. (F) Effects of PEPT1 inhibitor glycylsarcosine $(25 \mathrm{mM}$, Gly-Sar) or MCT6 inhibitor bumetanide $\left(250 \mu \mathrm{M}\right.$, BUM) on $\mathrm{P}_{\text {eff }}$ values in the intestine of normal rats (NOR) using SPIP with

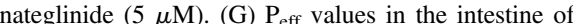
DM, HFD, and CON rats using SPIP with bumetanide $(5 \mu \mathrm{M})$. Data are presented as mean \pm S.D. $(n=6)$. ${ }^{*} P<0.05 ; * * P<0.01$ vs. CON or NOR; ${ }^{*} P<0.05$; ${ }^{\# \#} P<0.01$ vs. HFD.
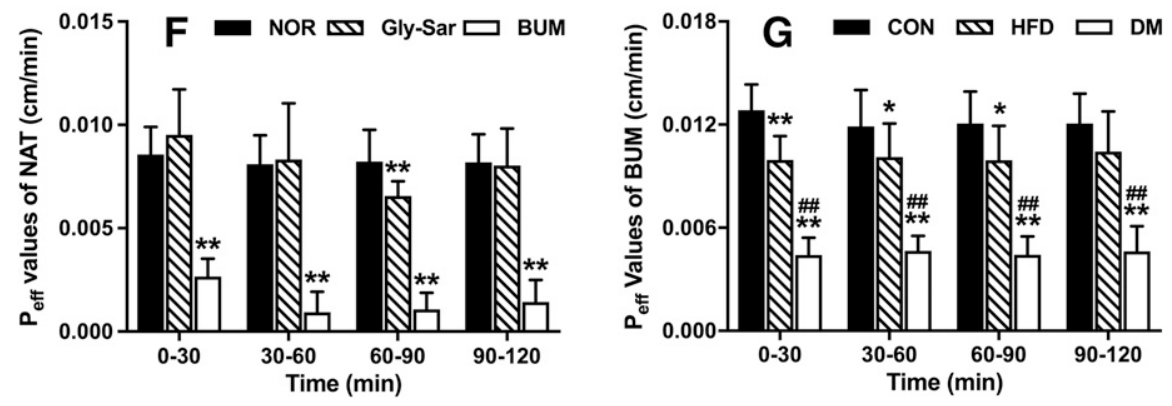

water were only $15.2 \%$ and $36.7 \%$ of those in normal rats, respectively (Table 2). We also found that the mean residence time and time to peak concentration $\left(T_{\max }\right)$ in rats drinking butyrate water were significantly shortened, but the $C_{\max }$ was not significantly altered. We also detected the protein levels of MCT6 and PPAR $\gamma$ (Fig. 4H). In accordance with our hypothesis, butyrate treatment down-regulated the expression of intestinal MCT6, accompanied by an increased PPAR $\gamma$ protein level. We also investigated the expression of PPAR $\gamma$ in DM, HFD, and CON rats using Western blot analysis (Fig. 4G). Similar alterations of MCT6 and PPAR $\gamma$ were found in the intestine of HFD and DM rats. Interestingly, the protein levels of PPAR $\gamma$ were negatively correlated with the MCT6 protein levels in the intestine of rats (Fig. 4I).

\section{Discussion}

The present study mainly reports that diabetes significantly decreases the expression and function of intestinal MCT6 in rats, leading to remarkably low oral plasma exposure of nateglinide. The DM rats displayed typical diabetic syndromes, including polydipsia, polyphagia, polyuria, as well as significant increase in liver weight, levels of FGB, TC, and TG, and HOMA-IR (Table 1), which reflected the characteristics and natural history of type II diabetes.

Nateglinide, a substrate of MCT6 (Kohyama et al., 2013), is mainly metabolized to M1 via hepatic CYP2C11 (orthologs of human CYP2C9) in rats. CYP3A1/2 (orthologs of human CYP3A4) also catalyzes M1 formation, although its contribution is minor. We first investigated nateglinide metabolism in the hepatic microsomes of rats. We found that M1 formation from nateglinide after 40 minutes of incubation with hepatic microsomes of rats accounted for about $77.2 \%$ of nateglinide depletion (Supplemental Fig. 1, A and B), demonstrating that M1 was the main metabolite of nateglinide, which was consistent with nateglinide metabolism in human hepatic microsomes (Takanohashi et al., 2007). Diabetes also significantly impaired M1 formation (Supplemental Fig. 1B). However, the $\mathrm{CL}_{\text {int }}$ values of nateglinide in $\mathrm{CON}$ rats and $\mathrm{DM}$ 


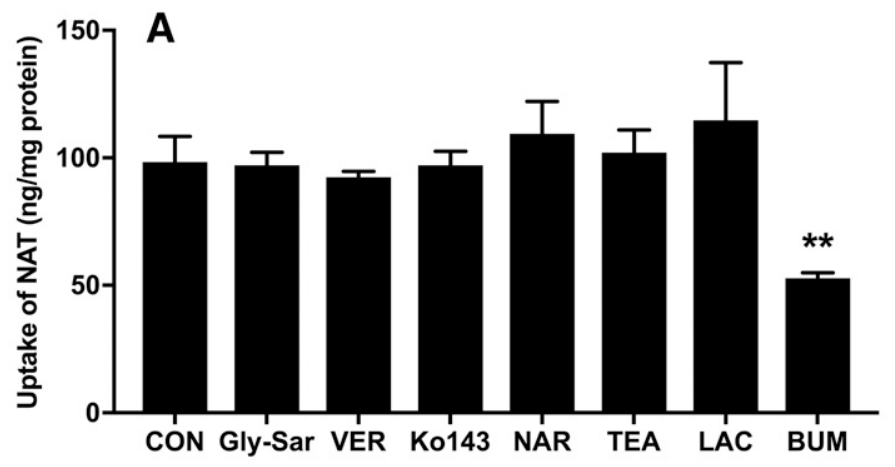

B
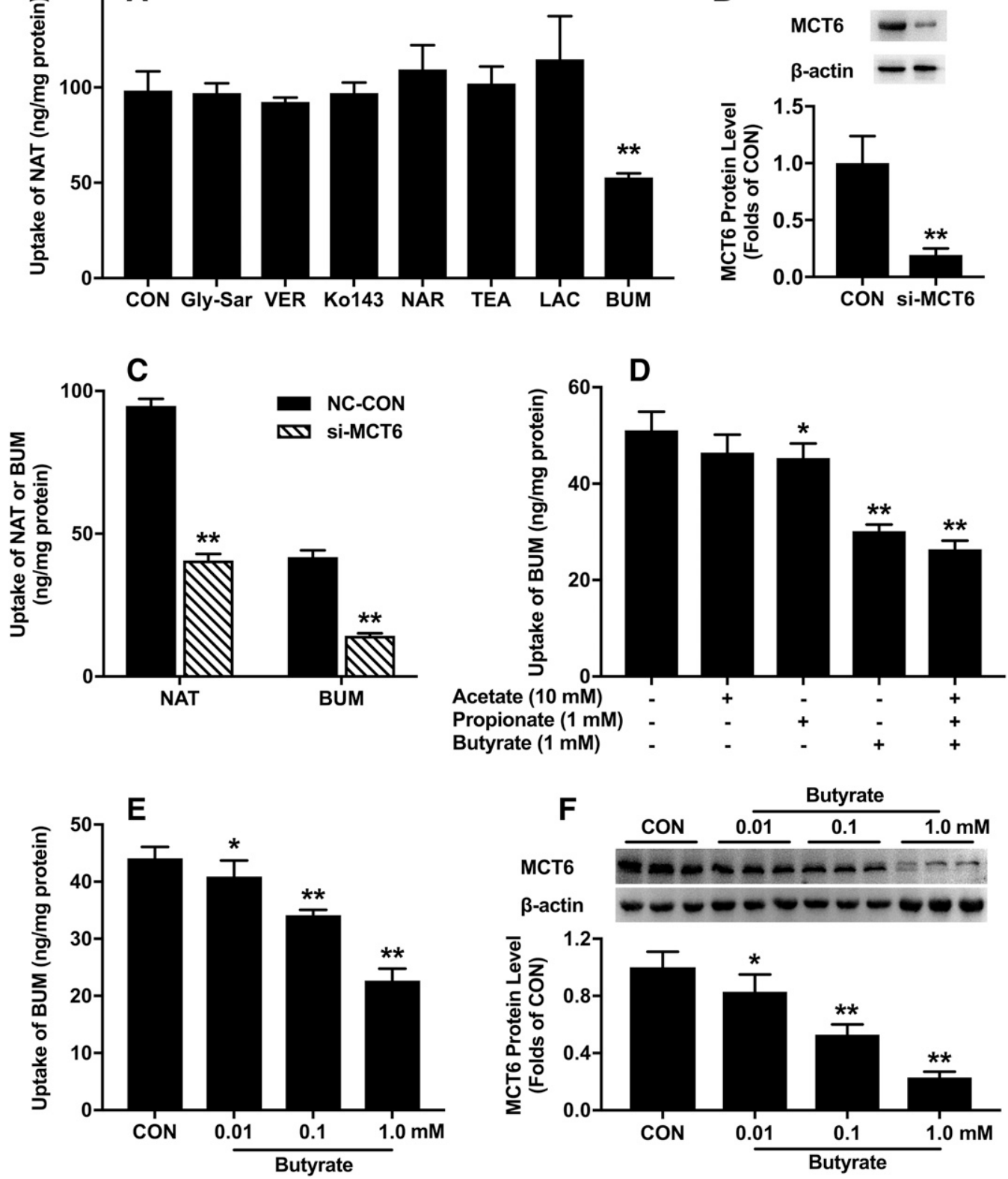

Fig. 3. Function and expression of MCT6 in Caco-2 cells. (A) Effects of several transporter inhibitors on the uptake of nateglinide (10 $\mu \mathrm{M})$ in Caco-2 cells. (B) Expression of MCT6 protein in Caco-2 cells transfected with and without MCT6 siRNA. (C) Uptake of nateglinide $(10 \mu \mathrm{M})$ and bumetanide $(50 \mu \mathrm{M})$ in Caco-2 cells transfected with negative control siRNA or MCT6 siRNA. (D) Effects of butyrate $(1 \mathrm{mM})$, propionate $(1 \mathrm{mM})$, acetate $(10 \mathrm{mM})$, and their mixture on the uptake of bumetanide $(50 \mu \mathrm{M})$ in Caco-2 cells. (E and F) Concentration-dependent effects of butyrate on the uptake of bumetanide $(50 \mu \mathrm{M})$ and expression of MCT6 protein in Caco-2 cells. Data are presented as mean \pm S.D. $(n=6)$. BUM, bumetanide; LAC, L-lactic acid; NAR, naringin; NAT, nateglinide; NC, negative control siRNA; si-MCT6, MCT6 siRNA; TEA, tetraethylammonium; VER, verapamil. $* P<0.05 ; * * P<0.01$ vs. CON

rats were comparable, which seemed to explain the findings that diabetes did not alter the pharmacokinetics of nateglinide after intravenous administration to Goto-Kakizaki rats (Tamura et al., 2010), but it could not explain the decrease in oral plasma exposure of nateglinide in DM rats (Fig. 1A; Table 2).

This study also illuminated that hepatic CYP3A was involved in metabolism of nateglinide, including M1 formation (Supplemental Fig. 1, D and F). Moreover, induction of hepatic CYP3A by diabetes was also reported (Xu et al., 2014; Shu et al., 2016b). These findings indicate that CYP3A induction under diabetic states might compensate for the alterations in $\mathrm{M} 1$ formation and nateglinide depletion mediated by down-regulation of CYP2C11 expression, which may partly explain how diabetes significantly decreased the expression of hepatic
CYP2C11 without affecting the $\mathrm{CL}_{\text {int }}$ values of nateglinide and the extent of the decrease in M1 formation was less than the reduction in hepatic CYP2C11 expression.

Next, we focused on intestinal absorption of nateglinide. In accordance with our expectations, the $\mathrm{P}_{\text {eff }}$ values of nateglinide in intestine of DM rats were only about $60 \%$ that of CON rats (Fig. 2A). Meanwhile, the DM rats showed lower mRNA and protein levels of intestinal PEPT1 and MCT6 (Fig. 2, C-E), indicating that the decreases of the two transporters might be the reason, at least in part, for impaired intestinal absorption of nateglinide. Further study showed that the PEPT1 inhibitor Gly-Sar did not affect the intestinal absorption of nateglinide (Fig. 2F), which was consistent with the previous report that PEPT1 was not involved in the transport of nateglinide (Terada et al., 2000). 


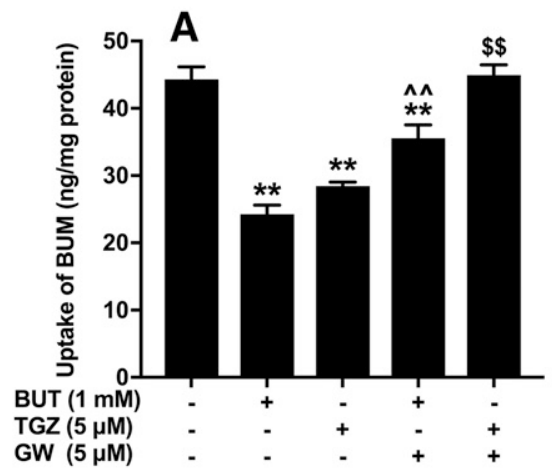

D
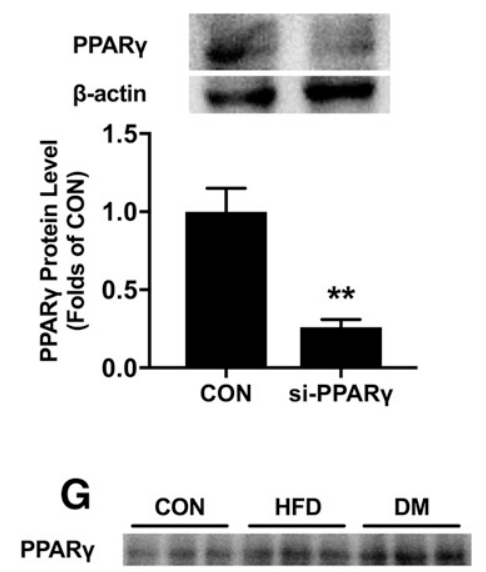

$\beta$-actin $\quad-\infty-\infty-\infty=0$

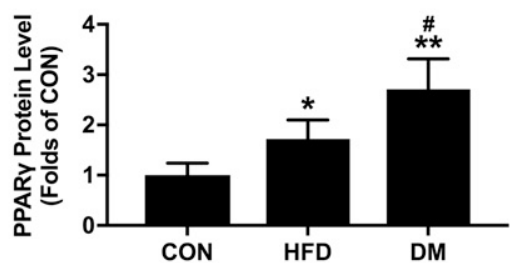

B

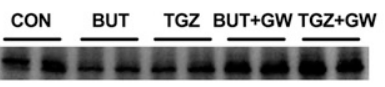

MCT6

$\beta$-actin
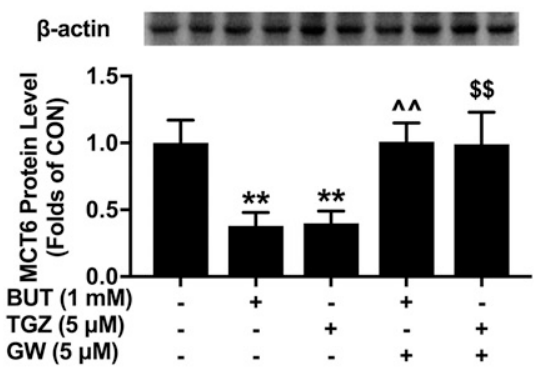

E
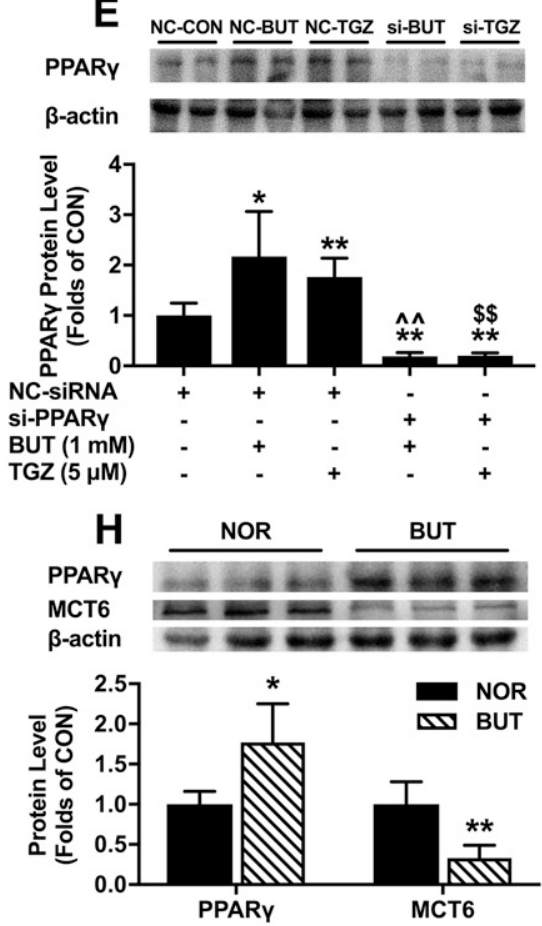
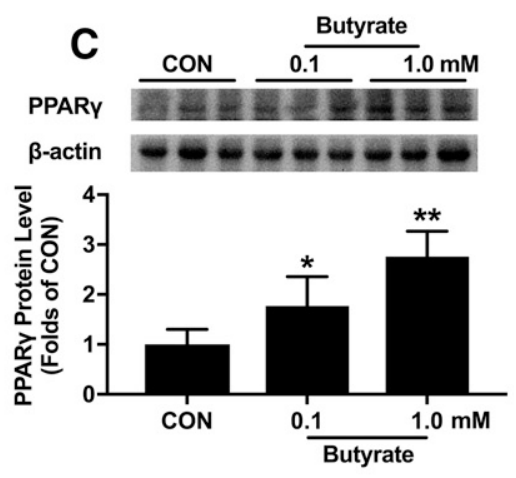

F
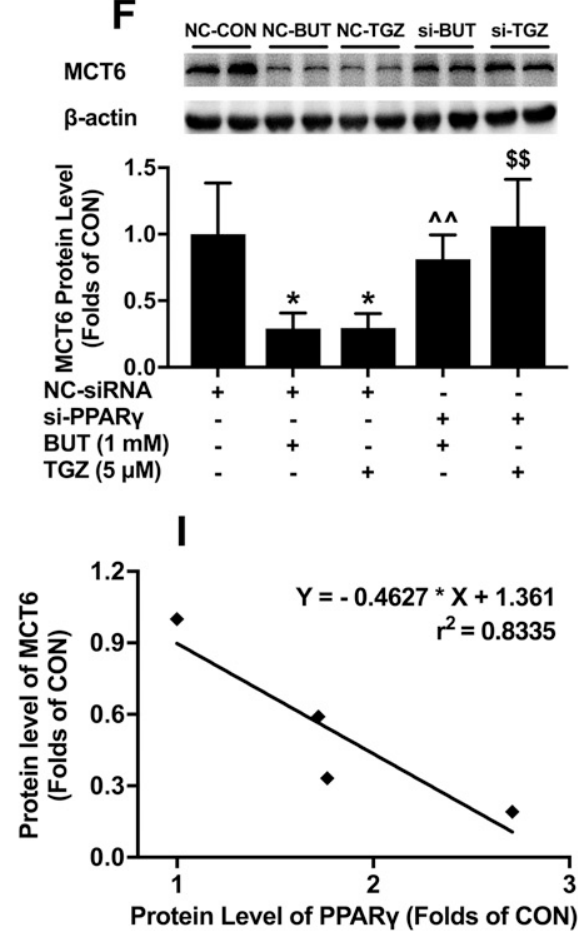

Fig. 4. Involvement of PPAR $\gamma$ in butyrate-MCT6 regulation. (A and B) Effects of butyrate (1 mM), troglitazone (5 $\mu \mathrm{M})$, and GW9662 (5 $\mu \mathrm{M})$ on the uptake of bumetanide $(50 \mu \mathrm{M})$ and expression of MCT6 protein in Caco-2 cells. (C) Concentration-dependent effects of butyrate on the expression of PPAR $\gamma$ protein in Caco-2 cells. (D) Expression of PPAR $\gamma$ protein in Caco-2 cells transfected with and without PPAR $\gamma$ siRNA. (E and F) Effects of butyrate $(1 \mathrm{mM})$ and troglitazone $(5 \mu \mathrm{M})$ on the protein levels of PPAR $\gamma$ and MCT6 in Caco-2 cells transfected with negative control siRNA or PPAR $\gamma$ siRNA. (G) Expression of PPAR $\gamma$ protein in intestine of DM, HFD, and CON rats. (H) Protein levels of PPAR $\gamma$ and MCT6 in the intestine of normal rats and rats drinking water containing butyrate (150 mM) for 4 weeks. (I) Correlation analysis for protein levels of PPAR $\gamma$ and MCT6 in CON, HFD, DM, and BUT rats. Data are presented as mean \pm S.D. $(n=6)$. BUT, butyrate; CON, control cells or control diet rats; GW, GW9662; NC-siRNA, negative control siRNA; NOR, normal rats; si-PPAR $\gamma$, PPAR $\gamma$ siRNA; TGZ, troglitazone. ${ }^{*} P<0.05$; $* * P<0.01$ vs. CON or NOR; ${ }^{*} P<0.05$; ${ }^{\#} P<0.01$ vs. HFD; ${ }^{\wedge} P<0.05 ;{ }^{\wedge} P<0.01$ vs. BUT or NC-BUT; ${ }^{\$} P<0.05 ;{ }^{\$} P<0.01$ vs. TGZ or NC-TGZ.

However, the MCT6 inhibitor bumetanide remarkably inhibited the absorption of nateglinide, whose $\mathrm{P}_{\text {eff }}$ values were only about $18 \%$ of those without bumetanide, indicating that the intestinal absorption of nateglinide was mainly (about $80 \%$ ) mediated by bumetanide-sensitive transporters and that simple diffusion accounted for less than $20 \%$ (Fig. 2F).

Bumetanide is used as probe substrate to estimate the function of MCT6 (Murakami et al., 2005), although it is also a substrate or inhibitor of other transporters in intestinal tissues, such as organic anion transporter 2 (OAT2), sodium-potassium-2chloride cotransporter 1 (NKCC1), multidrug resistance protein 4 (MRP4), and BCRP (Burckhardt, 2012; Tollner et al., 2015; Romermann et al., 2017; Nigam, 2018). Several reports have shown that neither OAT2 nor MRP4 mediate nateglinide transport (Uchida et al., 2007; Kimoto et al., 2018). No evidence has demonstrated that NKCC1 and BCRP mediate nateglinide transport. These results indicate that bumetanide decreased the intestinal absorption of nateglinide at least in part via inhibiting intestinal MCT6 activity.
The contributions of other transporters to intestinal absorption of nateglinide need further investigation. Additionally, previous reports have shown that diabetes remarkably enhances intestinal permeability in humans (Tian et al., 2016; Cox et al., 2017). Moreover, diabetes also impairs intestinal motility (Marathe et al., 2016), accompanied by a slow gastric emptying rate induced by hyperglycemia (Horvath et al., 2015). All these alterations may be reasons leading to the decreased intestinal absorption and plasma-concentration profile of nateglinide, which seemed to account for the inconsistency between the obvious reduction in MCT6 expression and the partly decreased $\mathrm{P}_{\text {eff }}$ values in intestinal of DM rats.

These findings implied that nateglinide absorption was mainly mediated by intestinal MCT6 and that the decrease in intestinal absorption of nateglinide by diabetes was mainly attributed to the down-regulation of intestinal MCT6 function. The down-regulation of intestinal MCT6 function by diabetes was further evidenced by the decreases in intestinal absorption of bumetanide in DM rats 
(Fig. 2G). Consistent with the pharmacokinetics of nateglinide in DM rats, coadministration of MCT6 inhibitor bumetanide also remarkably inhibited the oral plasma exposure of nateglinide in normal rats (Fig. 1C; Table 2). All these results demonstrate that diabetes decreased the oral plasma exposure of nateglinide mainly via down-regulating the expression and function of intestinal MCT6.

We further documented the role of MCT6 in the intestinal absorption of nateglinide using Caco- 2 cells. Only bumetanide significantly inhibited the uptake of nateglinide, while other transporter inhibitors, including Gly-Sar (for PEPT1), verapamil (for P-GP), Ko143 (for BCRP), naringin (for OATP1A2), tetraethylammonium (for OCTs), or L-lactic acid (for MCT1-4), did not show inhibitory effects (Fig. 3A). The silencing of MCT6 in Caco-2 cells further demonstrated the important role of MCT6 in the intestinal absorption of nateglinide and bumetanide (Fig. 3, B and C).

Previous studies reported that the $K_{\mathrm{m}}$ values of nateglinide uptake in Caco-2 cells (448 and $240 \mu \mathrm{M}$ ) (Okamura et al., 2002; Itagaki et al., 2005) were different from that in Xenopus oocytes injected MCT6cRNA $(45.9 \mu \mathrm{M})$ (Kohyama et al., 2013) and concluded that nateglinide uptake might be not mainly mediated by MCT6. This discrepancy might be the result of the cell source. For example, the transport characteristics of Xenopus oocytes were reported to be greatly different from Chinese hamster ovary cells and HEK-293 cells (Nieuweboer et al., 2014). Both OATP1B1 and OATP1B3 expressed in Chinese hamster ovary cells or HEK-293 cells mediated the transport of docetaxel, whereas in Xenopus oocytes OATP1B3 but not OATP1B1 mediated the transport of docetaxel. Moreover, there would be almost twice the variability in $K_{\mathrm{m}}$ values of Caco-2 cells from the two reports, even if the same cells were used (Okamura et al., 2002; Itagaki et al., 2005). Of course, the roles of other intestinal transporters of nateglinide cannot be excluded.

SCFA are important end products that mainly produced by gut flora, which involves the intestinal anaerobic fermentation of indigestible peptides and fiber in the diet (Cummings et al., 1987). In the process, fermentation is easily influenced by plentiful physiologic and environmental factors, including species and interaction of gut flora, disease progress, diet, and physical properties of the intestinal microenvironment (Jandhyala et al., 2015; O'Toole and Jeffery, 2015; Villanueva-Millan et al., 2015). Our study illustrated that HFD feeding and diabetes obviously augmented the amount of SCFA in small intestinal content of rats, especially butyrate (Table 1 ). This was consistent with the previous reports that obesity up-regulated SCFA in the feces of mice and humans (Fernandes et al., 2014; Li et al., 2014), and that diabetes also up-regulated acetate in the feces of kids (Samuelsson and Ludvigsson, 2004).

We further investigated the effects of SCFA, including butyrate, propionate, acetate, and their mixture, on MCT6 function in Caco- 2 cells using the uptake of bumetanide (Fig. 3D). The results demonstrated that the butyrate and SCFA mixture showed similar inhibition on bumetanide uptake in Caco-2 cells, implying that the inhibition of MCT6 function by SCFA was mainly attributed to butyrate. Furthermore, butyrate concentration-dependently decreased the expression and function of MCT6 in Caco-2 cells (Fig. 3, E and F).

Previous reports (Wachtershauser et al., 2000; Kinoshita et al., 2002; Marion-Letellier et al., 2008; Tylichova et al., 2017) implied the latent activation of PPAR $\gamma$ by butyrate. We further investigated whether activation of PPAR $\gamma$ was also involved in butyrate-mediated MCT6 down-regulation. In accordance with the previous reports (Wachtershauser et al., 2000; Marion-Letellier et al., 2008), both butyrate and troglitazone induced protein expression of PPAR $\gamma$ in Caco-2 cells (Fig. 4, C and E). Moreover, butyrate and troglitazone down-regulated the expression and function of MCT6, which were attenuated by the PPAR $\gamma$ antagonist GW9662 (Fig. 4, A and B). In accordance with our expectations, neither troglitazone nor butyrate could decrease MCT6 expression in Caco-2 cells silenced with PPAR $\gamma$ siRNA (Fig. 4, E and F), confirming the involvement of PPAR $\gamma$ activation in butyratemediated MCT6 down-regulation.

The role of butyrate in intestinal MCT6 expression and function was further confirmed by the alteration in oral pharmacokinetics of nateglinide in rats drinking water containing butyrate for 4 weeks. This was consistent with the data from DM rats that butyrate treatment significantly decreased the oral plasma exposure of nateglinide and M1 (Fig. 1, E and $\mathrm{F}$; Table 2). We was also noticed that butyrate treatment remarkably shortened the $T_{\max }$ and mean residence time values of nateglinide in rats, which was possibly due to the improvement of intestinal motility by high-concentration butyrate (Canani et al., 2011), which in turn increased the absorptive rate of nateglinide. Rats after butyrate treatment also showed lower intestinal MCT6 and higher PPAR $\gamma$ (Fig. 4H).

We further detected the expression of intestinal PPAR $\gamma$ protein in DM rats. Inconsistent with the CON rats, higher expression of intestinal PPAR $\gamma$ protein was also seen in DM rats (Fig. 4G). Furthermore, the expression of intestinal MCT6 was negatively correlated with the intestinal PPAR $\gamma$ protein levels in rats (Fig. 4I).

Although the clinical significance of impaired MCT6 by increased butyrate in diabetic rats is still unclear, it seems to be a reason for the oral plasma exposure of MCT6 substrates (azosemide and furosemide) and diuretic efficacy being attenuated significantly in diabetic rats (induced by alloxan) in previous studies (Park et al., 1996, 1998). These results indicate that the clinical dose of MCT6 substrates should be further considered under diabetic states.

In conclusion, diabetes significantly down-regulated the expression and function of intestinal MCT6 in rats, decreasing the oral plasma exposure of nateglinide. The impairment of MCT6 function and expression by diabetes was partly involved in butyrate-mediated $\operatorname{PPAR} \gamma$ activation.

\section{Acknowledgments}

We thank Jiang Cheng's laboratory for kind support metabolite M1. All participants had no conflicts of interest.

\section{Authorship Contributions}

Participated in research design: Xu, L. Liu, X. Liu.

Conducted experiments: Xu, Xuan, Zhu, Qian, Zhou, Geng, Li, Wu, Zhao, Kong, Liang.

Contributed new reagents or analytic tools: $\mathrm{Xu}$, Jiang.

Performed data analysis: Xu, Xuan, Zhu.

Wrote or contributed to the writing of the manuscript: Xu, L. Liu, X. Liu.

\section{References}

Bergman EN (1990) Energy contributions of volatile fatty acids from the gastrointestinal tract in various species. Physiol Rev 70:567-590.

Bonen A (2000) Lactate transporters (MCT proteins) in heart and skeletal muscles. Med Sci Sports Exerc 32:778-789.

Bonen A, Heynen M, and Hatta H (2006) Distribution of monocarboxylate transporters MCT1MCT8 in rat tissues and human skeletal muscle. Appl Physiol Nutr Metab 31:31-39.

Burckhardt G (2012) Drug transport by organic anion transporters (OATs). Pharmacol Ther 136: $106-130$.

Canani RB, Costanzo MD, Leone L, Pedata M, Meli R, and Calignano A (2011) Potential beneficial effects of butyrate in intestinal and extraintestinal diseases. World J Gastroenterol 17:1519-1528.

Cox AJ, Zhang P, Bowden DW, Devereaux B, Davoren PM, Cripps AW, and West NP (2017) Increased intestinal permeability as a risk factor for type 2 diabetes. Diabetes Metab 43:163-166. Cummings JH, Pomare EW, Branch WJ, Naylor CP, and Macfarlane GT (1987) Short chain fatty acids in human large intestine, portal, hepatic and venous blood. Gut 28:1221-1227.

Estudante M, Morais JG, Soveral G, and Benet LZ (2013) Intestinal drug transporters: an overview. Adv Drug Deliv Rev 65:1340-1356.

Fernandes J, Su W, Rahat-Rozenbloom S, Wolever TM, and Comelli EM (2014) Adiposity, gut microbiota and faecal short chain fatty acids are linked in adult humans. Nutr Diabetes 4:e121. Fukushima A, Aizaki Y, and Sakuma K (2009) Short-chain fatty acids induce intestinal transient receptor potential vanilloid type 6 expression in rats and Caco-2 cells. J Nutr 139:20-25. Halas CJ (2001) Nateglinide. Am J Health Syst Pharm 58:1200-1205.

Hamer HM, Jonkers D, Venema K, Vanhoutvin S, Troost FJ, and Brummer RJ (2008) Review article: the role of butyrate on colonic function. Aliment Pharmacol Ther 27:104-119.

Horváth VJ, Putz Z, Izbéki F, Körei AE, Gerő L, Lengyel C, Kempler P, and Várkonyi T (2015) Diabetesrelated dysfunction of the small intestine and the colon: focus on motility. Curr Diab Rep 15:94. 
Hu N, Xie S, Liu L, Wang X, Pan X, Chen G, Zhang L, Liu H, Liu X, Liu X, et al. (2011) Opposite effect of diabetes mellitus induced by streptozotocin on oral and intravenous pharmacokinetics of verapamil in rats. Drug Metab Dispos 39:419-425.

Itagaki S, Otsuka Y, Kubo S, Okumura H, Saito Y, Kobayashi M, Hirano T, and Iseki K (2005) Intestinal uptake of nateglinide by an intestinal fluorescein transporter. Biochim Biophys Acta 1668:190-194.

Jandhyala SM, Talukdar R, Subramanyam C, Vuyyuru H, Sasikala M, and Nageshwar Reddy D (2015) Role of the normal gut microbiota. World J Gastroenterol 21:8787-8803.

Jappar D, Wu SP, Hu Y, and Smith DE (2010) Significance and regional dependency of peptide transporter (PEPT) 1 in the intestinal permeability of glycylsarcosine: in situ single-pass perfusion studies in wild-type and Pept1 knockout mice. Drug Metab Dispos 38:1740-1746.

Jones RS, Parker MD, and Morris ME (2017) Quercetin, morin, luteolin, and phloretin are dietary flavonoid inhibitors of monocarboxylate transporter 6. Mol Pharm 14:2930-2936.

Jouan E, Le Vee M, Denizot C, Da Violante G, and Fardel O (2014) The mitochondrial fluorescent dye rhodamine 123 is a high-affinity substrate for organic cation transporters (OCTs) 1 and 2. Fundam Clin Pharmacol 28:65-77.

Jung TH, Park JH, Jeon WM, and Han KS (2015) Butyrate modulates bacterial adherence on LS174T human colorectal cells by stimulating mucin secretion and MAPK signaling pathway. Nutr Res Pract 9:343-349.

Karara AH, Dunning BE, and McLeod JF (1999) The effect of food on the oral bioavailability and the pharmacodynamic actions of the insulinotropic agent nateglinide in healthy subjects. $J$ Clin Pharmacol 39:172-179.

Keku TO, Dulal S, Deveaux A, Jovov B, and Han X (2015) The gastrointestinal microbiota and colorectal cancer. Am J Physiol Gastrointest Liver Physiol 308:G351-G363.

Kelly CJ, Zheng L, Campbell EL, Saeedi B, Scholz CC, Bayless AJ, Wilson KE, Glover LE, Kominsky DJ, Magnuson A, et al. (2015) Crosstalk between microbiota-derived short-chain fatty acids and intestinal epithelial HIF augments tissue barrier function. Cell Host Microbe 17:662-671.

Kimoto E, Mathialagan S, Tylaska L, Niosi M, Lin J, Carlo AA, Tess DA, and Varma MVS (2018) Organic anion transporter 2-mediated hepatic uptake contributes to the clearance of highpermeability-low-molecular-weight acid and zwitterion drugs: evaluation using 25 drugs. $J$ Pharmacol Exp Ther 367:322-334.

Kimura O, Fujii Y, Haraguchi K, Kato Y, Ohta C, Koga N, and Endo T (2017) Uptake of perfluorooctanoic acid by Caco-2 cells: involvement of organic anion transporting polypeptides. Toxicol Lett 277:18-23.

Kimura O, Tsukagoshi K, and Endo T (2009) Uptake of phenoxyacetic acid derivatives into Caco-2 cells by the monocarboxylic acid transporters. Toxicol Lett 189:102-109.

Kinoshita M, Suzuki Y, and Saito Y (2002) Butyrate reduces colonic paracellular permeability by enhancing PPARgamma activation. Biochem Biophys Res Commun 293:827-831.

Kliewer SA, Lenhard JM, Willson TM, Patel I, Morris DC, and Lehmann JM (1995) A prostaglandin $\mathbf{J} 2$ metabolite binds peroxisome proliferator-activated receptor gamma and promotes adipocyte differentiation. Cell 83:813-819.

Kohyama N, Shiokawa H, Ohbayashi M, Kobayashi Y, and Yamamoto T (2013) Characterization of monocarboxylate transporter 6: expression in human intestine and transport of the antidiabetic drug nateglinide. Drug Metab Dispos 41:1883-1887.

Li M, Gu D, Xu N, Lei F, Du L, Zhang Y, and Xie W (2014) Gut carbohydrate metabolism instead of fat metabolism regulated by gut microbes mediates high-fat diet-induced obesity. Benef Microbes 5:335-344.

Liu H, Liu L, Li J, Mei D, Duan R, Hu N, Guo H, Zhong Z, and Liu X (2012) Combined contributions of impaired hepatic CYP2C11 and intestinal breast cancer resistance protein activities and expression to increased oral glibenclamide exposure in rats with streptozotocininduced diabetes mellitus. Drug Metab Dispos 40:1104-1112.

Livak KJ and Schmittgen TD (2001) Analysis of relative gene expression data using real-time quantitative PCR and the $2^{-\Delta \Delta C(T)}$ method. Methods 25:402-408.

Louis P, Hold GL, and Flint HJ (2014) The gut microbiota, bacterial metabolites and colorectal cancer. Nat Rev Microbiol 12:661-672.

Lucas S, Omata Y, Hofmann J, Böttcher M, Iljazovic A, Sarter K, Albrecht O, Schulz O, Krishnacoumar B, Krönke G, et al. (2018) Short-chain fatty acids regulate systemic bone mass and protect from pathological bone loss. Nat Commun 9:55.

Macfarlane GT and Macfarlane S (2012) Bacteria, colonic fermentation, and gastrointestinal health. J AOAC Int 95:50-60.

Marathe CS, Rayner CK, Jones KL, and Horowitz M (2016) Novel insights into the effects of diabetes on gastric motility. Expert Rev Gastroenterol Hepatol 10:581-593.

Marion-Letellier R, Butler M, Déchelotte P, Playford RJ, and Ghosh S (2008) Comparison of cytokine modulation by natural peroxisome proliferator-activated receptor gamma ligands with synthetic ligands in intestinal-like Caco-2 cells and human dendritic cells--potential for dietary modulation of peroxisome proliferator-activated receptor gamma in intestinal inflammation. $A m$ I Clin Nutr 87:939-948.

Martignoni M, Groothuis GMM, and de Kanter R (2006) Species differences between mouse, rat, dog, monkey and human CYP-mediated drug metabolism, inhibition and induction. Expert Opin Drug Metab Toxicol 2:875-894.

Miwa $\mathrm{H}$ (2002) High-performance liquid chromatographic determination of free fatty acids and esterified fatty acids in biological materials as their 2-nitrophenylhydrazides. Anal Chim Acta 465:237-255.

Murakami Y, Kohyama N, Kobayashi Y, Ohbayashi M, Ohtani H, Sawada Y, and Yamamoto T (2005) Functional characterization of human monocarboxylate transporter 6 (SLC16A5). Drug Metab Dispos 33:1845-1851

Nieuweboer AJ, Hu S, Gui C, Hagenbuch B, Ghobadi Moghaddam-Helmantel IM, Gibson AA, de Bruijn P, Mathijssen RH, and Sparreboom A (2014) Influence of drug formulation on OATP1Bmediated transport of paclitaxel. Cancer Res 74:3137-3145

Nigam SK (2018) The SLC22 transporter family: a paradigm for the impact of drug transporters on metabolic pathways, signaling, and disease. Annu Rev Pharmacol Toxicol 58:663-687.

Ogihara T, Kano T, Wagatsuma T, Wada S, Yabuuchi H, Enomoto S, Morimoto K, Shirasaka Y, Kobayashi S, and Tamai I (2009) Oseltamivir (tamiflu) is a substrate of peptide transporter 1. Drug Metab Dispos 37:1676-1681.

Okamura A, Emoto A, Koyabu N, Ohtani H, and Sawada Y (2002) Transport and uptake of nateglinide in Caco-2 cells and its inhibitory effect on human monocarboxylate transporte MCT1. Br J Pharmacol 137:391-399.

O'Toole PW and Jeffery IB (2015) Gut microbiota and aging. Science 350:1214-1215.

Park JH, Lee WI, Yoon WH, Park YD, Lee JS, and Lee MG (1998) Pharmacokinetic and pharmacodynamic changes of furosemide after intravenous and oral administration to rats with alloxan-induced diabetes mellitus. Biopharm Drug Dispos 19:357-364.
Park KJ, Yoon WH, Shin WG, and Lee MG (1996) Pharmacokinetics and pharmacodynamics of azosemide after intravenous and oral administration to rats with alloxan-induced diabetes mellitus. J Pharm Pharmacol 48:1093-1097.

Peng L, Li ZR, Green RS, Holzman IR, and Lin J (2009) Butyrate enhances the intestinal barrier by facilitating tight junction assembly via activation of AMP-activated protein kinase in Caco-2 cell monolayers. J Nutr 139:1619-1625.

Posada MM and Smith DE (2013) Relevance of PepT1 in the intestinal permeability and oral absorption of cefadroxil. Pharm Res 30:1017-1025.

Ríos-Covián D, Ruas-Madiedo P, Margolles A, Gueimonde M, de Los Reyes-Gavilán CG, and Salazar N (2016) Intestinal short chain fatty acids and their link with diet and human health. Front Microbiol 7:185.

Römermann K, Fedrowitz M, Hampel P, Kaczmarek E, Töllner K, Erker T, Sweet DH, and Löscher W (2017) Multiple blood-brain barrier transport mechanisms limit bumetanide accumulation, and therapeutic potential, in the mammalian brain. Neuropharmacology 117:182-194.

Samuelsson U and Ludvigsson J (2004) The concentrations of short-chain fatty acids and other microflora-associated characteristics in faeces from children with newly diagnosed type $1 \mathrm{di}-$ abetes and control children and their family members. Diabet Med 21:64-67.

Schwab M, Reynders V, Ulrich S, Zahn N, Stein J, and Schröder O (2006) PPAR $\gamma$ is a key target of butyrate-induced caspase-3 activation in the colorectal cancer cell line Caco-2. Apoptosis 11:1801-1811.

Shu N, Hu M, Ling Z, Liu P, Wang F, Xu P, Zhong Z, Sun B, Zhang M, Li F, et al. (2016a) The enhanced atorvastatin hepatotoxicity in diabetic rats was partly attributed to the upregulated hepatic Cyp3a and SLCO1B1. Sci Rep 6:33072.

Shu N, Hu M, Liu C, Zhang M, Ling Z, Zhang J, Xu P, Zhong Z, Chen Y, Liu L, et al. (2016b) Decreased exposure of atorvastatin in diabetic rats partly due to induction of hepatic Cyp3a and Oatp2. Xenobiotica 46:875-881.

Sutton SC, Rinaldi MTS, and Vukovinsky KE (2001) Comparison of the gravimetric, phenol red, and 14C-PEG-3350 methods to determine water absorption in the rat single-pass intestinal perfusion model. AAPS PharmSci 3:E25.

Takanohashi T, Koizumi T, Mihara R, and Okudaira K (2007) Prediction of the metabolic interaction of nateglinide with other drugs based on in vitro studies. Drug Metab Pharmacokinet 22:409-418.

Tamura M, Shiba S, Kudo N, and Kawashima Y (2010) Pharmacokinetics of nateglinide enantiomers and their metabolites in Goto-Kakizaki rats, a model for type 2 diabetes mellitus. Chirality 22:92-98.

Terada T, Sawada K, Saito H, Hashimoto Y, and Inui K (2000) Inhibitory effect of novel ora hypoglycemic agent nateglinide (AY4166) on peptide transporters PEPT1 and PEPT2. Eur J Pharmacol 392:11-17.

Tian P, Li B, He C, Song W, Hou A, Tian S, Meng X, Li K, and Shan Y (2016) Antidiabetic (type 2) effects of Lactobacillus G15 and Q14 in rats through regulation of intestinal permeability and microbiota. Food Funct 7:3789-3797.

Töllner K, Brandt C, Römermann K, and Löscher W (2015) The organic anion transport inhibitor probenecid increases brain concentrations of the NKCC1 inhibitor bumetanide. Eur J Pharmacol 746: $167-173$.

Tsukagoshi K, Kimura O, and Endo T (2014) Steric hindrance of 2,6-disubstituted benzoic acid derivatives on the uptake via monocarboxylic acid transporters from the apical membranes of Caco-2 cells. Pestic Biochem Physiol 111:38-42.

Tylichová Z, Straková N, Vondráček J, Vaculová AH, Kozubík A, and Hofmanová J (2017) Activation of autophagy and PPAR $\gamma$ protect colon cancer cells against apoptosis induced by interactive effects of butyrate and DHA in a cell type-dependent manner: the role of cell differentiation. $J$ Nutr Biochem 39:145-155.

Uchida Y, Kamiie J, Ohtsuki S, and Terasaki T (2007) Multichannel liquid chromatographytandem mass spectrometry cocktail method for comprehensive substrate characterization of multidrug resistance-associated protein 4 transporter. Pharm Res 24:2281-2296.

Ulrich S, Wächtershäuser A, Loitsch S, von Knethen A, Brüne B, and Stein J (2005) Activation of PPAR $\gamma$ is not involved in butyrate-induced epithelial cell differentiation. Exp Cell Res 310: 196-204.

Vara D, Morell C, Rodríguez-Henche N, and Diaz-Laviada I (2013) Involvement of PPAR $\gamma$ in the antitumoral action of cannabinoids on hepatocellular carcinoma. Cell Death Dis 4:e618.

Villanueva-Millán MJ, Pérez-Matute P, and Oteo JA (2015) Gut microbiota: a key player in health and disease. A review focused on obesity. J Physiol Biochem 71:509-525.

Wächtershäuser A, Loitsch SM, and Stein J (2000) PPAR-gamma is selectively upregulated in Caco-2 cells by butyrate. Biochem Biophys Res Commun 272:380-385.

Wen JH, Wei XH, Sheng XY, Zhou DQ, Peng HW, Lu YN, and Zhou J (2015) Effect of ursolic acid on breast cancer resistance protein-mediated transport of rosuvastatin in vivo and vitro. Chin Med Sci J 30:218-225.

Xu D, Li F, Zhang M, Zhang J, Liu C, Hu MY, Zhong ZY, Jia LL, Wang DW, Wu J, et al. (2014) Decreased exposure of simvastatin and simvastatin acid in a rat model of type 2 diabetes. Acto Pharmacol Sin 35:1215-1225.

Zhang Y, Wang C, Liu Z, Meng Q, Huo X, Liu Q, Sun P, Yang X, Sun H, Ma X, et al. (2018) P-gp is involved in the intestinal absorption and biliary excretion of afatinib in vitro and in rats. Pharmacol Rep 70:243-250.

Zhong ZY, Sun BB, Shu N, Xie QS, Tang XG, Ling ZL, Wang F, Zhao KJ, Xu P, Zhang M, et al (2016) Ciprofloxacin blocked enterohepatic circulation of diclofenac and alleviated NSAIDinduced enteropathy in rats partly by inhibiting intestinal $\beta$-glucuronidase activity. Acta Pharmacol Sin 37:1002-1012.

Ziegler K, Kerimi A, Poquet L, and Williamson G (2016) Butyric acid increases transepithelia transport of ferulic acid through upregulation of the monocarboxylate transporters SLC16A1 (MCT1) and SLC16A3 (MCT4). Arch Biochem Biophys 599:3-12.

Address correspondence to: Li Liu, Center of Drug Metabolism and Pharmacokinetics, School of Pharmacy, China Pharmaceutical University, 24 Tongjia Lane, Gulou Distract, Nanjing, Jiangsu Province, People's Republic of China. E-mail: liulee@yeah.net; or Xiaodong Liu, Center of Drug Metabolism and Pharmacokinetics, School of Pharmacy, China Pharmaceutical University, 24 Tongjia Lane, Gulou Distract, Nanjing, Jiangsu Province, People's Republic of China. E-mail: xdliu@ cpu.edu.cn 